$\mathcal{E}_{\text {Iransport Forum }}^{\text {International }}$

\title{
Automation of the Driving Task
}

Some possible consequences and governance challenges

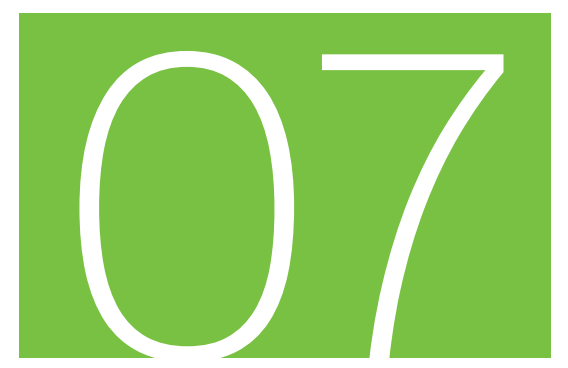

Discussion Paper 2017• 07

Tom Cohen and Clémence Cavoli

UCL Centre for Transport

Studies, London, UK 


\title{
E International Transport Forum
}

\author{
Automation of the driving task

\section{Some possible consequences and governance challenges}

Discussion Paper No. 2017-07

Prepared for the Roundtable on

Cooperative Mobility Systems and Automated Driving (6-7 December 2016)

Tom Cohen \& Clémence Cavoli

UCL Centre for Transport Studies, London, UK

July 2017 


\section{The International Transport Forum}

The International Transport Forum is an intergovernmental organisation with 59 member countries. It acts as a think tank for transport policy and organises the Annual Summit of transport ministers. ITF is the only global body that covers all transport modes. The ITF is politically autonomous and administratively integrated with the OECD.

The ITF works for transport policies that improve peoples' lives. Our mission is to foster a deeper understanding of the role of transport in economic growth, environmental sustainability and social inclusion and to raise the public profile of transport policy.

The ITF organises global dialogue for better transport. We act as a platform for discussion and prenegotiation of policy issues across all transport modes. We analyse trends, share knowledge and promote exchange among transport decision-makers and civil society. The ITF's Annual Summit is the world's largest gathering of transport ministers and the leading global platform for dialogue on transport policy.

The Members of the Forum are: Albania, Armenia, Argentina, Australia, Austria, Azerbaijan, Belarus, Belgium, Bosnia and Herzegovina, Bulgaria, Canada, Chile, China (People's Republic of), Croatia, Czech Republic, Denmark, Estonia, Finland, France, Former Yugoslav Republic of Macedonia, Georgia, Germany, Greece, Hungary, Iceland, India, Ireland, Israel, Italy, Japan, Kazakhstan, Korea, Latvia, Liechtenstein, Lithuania, Luxembourg, Malta, Mexico, Republic of Moldova, Montenegro, Morocco, the Netherlands, New Zealand, Norway, Poland, Portugal, Romania, Russian Federation, Serbia, Slovak Republic, Slovenia, Spain, Sweden, Switzerland, Turkey, Ukraine, the United Arab Emirates, the United Kingdom and the United States.

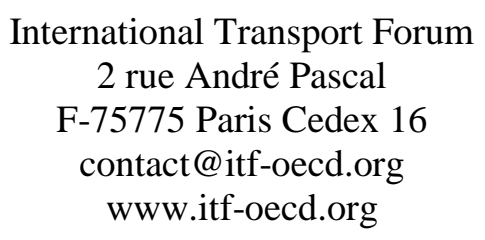

\section{ITF Discussion Papers}

ITF Discussion Papers make economic research, commissioned or carried out in-house at ITF, available to researchers and practitioners. They describe preliminary results or research in progress by the author(s) and are published to stimulate discussion on a broad range of issues on which the ITF works. Any findings, interpretations and conclusions expressed herein are those of the authors and do not necessarily reflect the views of the International Transport Forum or the OECD. Neither the OECD, ITF nor the authors guarantee the accuracy of any data or other information contained in this publication and accept no responsibility whatsoever for any consequence of their use. This document and any map included herein are without prejudice to the status of or sovereignty over any territory, to the delimitation of international frontiers and boundaries and to the name of any territory, city or area. Comments on Discussion Papers are welcome. 


\section{Acknowledgements}

The authors are grateful to the UK Department for Transport for permitting the sharing of findings from the work on social and behavioural questions relating to automated vehicles. They also thank Professor Peter Jones and Professor Benjamin Heydecker for helpful comments and technical advice.

Any errors are the responsibility of the authors themselves.

Whilst this paper arises from work carried out for the Department for Transport, the views reported are those of the authors and not of the Department. 


\begin{abstract}
The possible consequences of the advent of fully automated vehicles (AVs) for personal transport are assessed. A shared-user model is considered preferable to an owner-user model; public-sector intervention is considered necessary to secure the successful integration of AVs with mass transit. Interurban expressways are found to offer a better opportunity than urban roads of capturing the vehicles' potential traffic and safety benefits. AVs' performance in a mixed-fleet scenario is highly dependent on segregation from other road users, but segregation poses significant challenges.

The governance of a range of themes (such as demand management and security) is considered. In each case, challenges to achieving a socially desirable outcome are identified. Both laissez-faire and more interventionist styles of governance with respect to AVs present problems but laissez faire may carry greater risk. Decisions on governance should be based on meaningful dialogue with those who stand to be affected.
\end{abstract}




\section{Table of Contents}

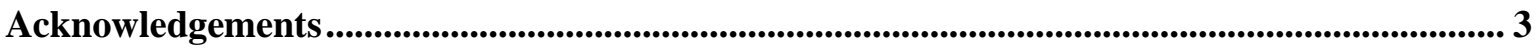

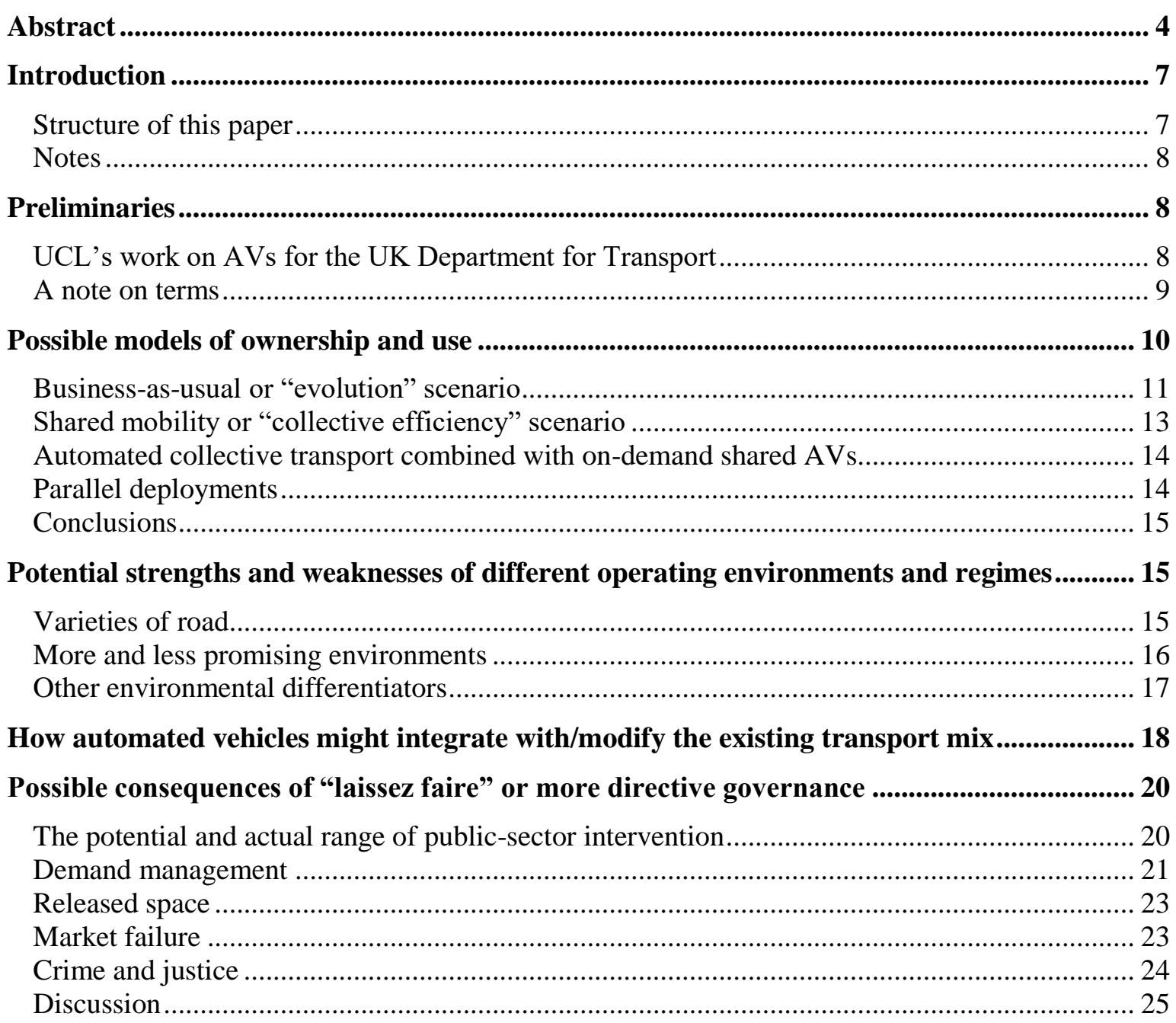

What "optimum" might mean and challenges authorities will need to address in attempting to

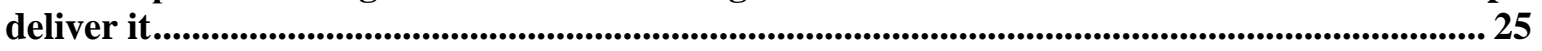

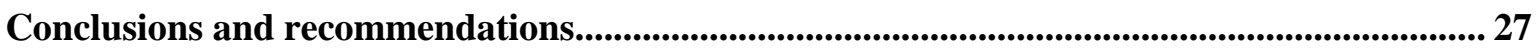

References ............................................................................................................................................. 30

Appendix - conceptual framework..................................................................................................................... 36

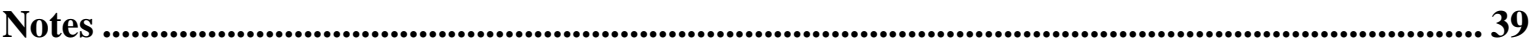

Figures 
Figure 1. Automation, autonomy, control, connectedness ...................................................... 10

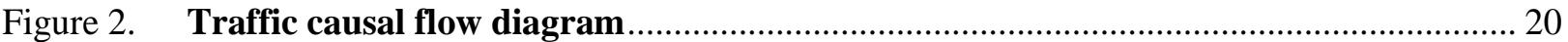

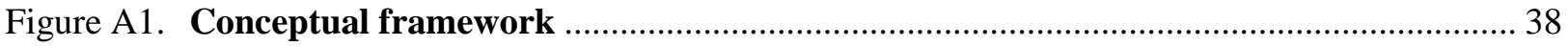




\section{Introduction}

Automated vehicles (AVs) are receiving an increasing amount of attention. For example, a literature review conducted as part of a project for the UK Department for Transport (see below) discovered four times as many items produced in 2015 as in 2003. This is hardly surprising, given the ongoing development of the Google Car, recent news involving Tesla's Autopilot, Volvo's Drive Me project and so on. In the UK in particular, the creation by the Government of the Centre for Connected and Autonomous Vehicles, followed by the initiation of some major research and development projects, has considerably increased interest in this topic.

It is understandable that most of the writing on the theme centres on the technology, how it will work and what it will offer. To a limited extent, this is accompanied by prediction and speculation about the possible consequences of AVs arriving, in terms of network impacts, likely safety effects and other of the more immediate transport outcomes. Where writing - both the academic and grey literatures - is weak is on the broader effects and, in particular, the question of how this technology could and should be governed. This, again, is not surprising: the technology is in its infancy so there is a natural focus on it rather than its implications. But the current paper is predicated on the principle that it is better to think about governance early, even if this is an inevitably speculative and tentative business. The alternative "technological determinism" - is to assume that it will be possible (and preferable) to react to developments as they arise. The major criticism of anticipatory governance is that the wrong assumptions will be made, leading to policies that prove inappropriate. But this can be managed by allowing for several possible futures and seeking policies that will be effective across all, as expressed by the UK Government's own Horizon Scanning Programme team:

"It's not about making predictions, but systematically investigating evidence about future trends. Horizon scanning helps government to analyse whether it is adequately prepared for potential opportunities and threats. This helps ensure that policies are resilient to different future environments" (GOV.UK n.d.).

\section{Structure of this paper}

This paper begins with a brief summary of work done for the UK Department for Transport which has served as a point of departure for what is discussed in subsequent sections.

The paper then moves into a set of five themed discussions:

- Possible models of ownership and use

- Potential strengths and weaknesses of different operating environments and regimes

- How automated vehicles might integrate with/modify the existing transport mix

- Possible consequences of "laissez faire" or more directive governance 
- What "optimum" might mean and challenges authorities will need to address in attempting to deliver it

Though government/governance is explicitly mentioned in the titles of only the final two themes, it permeates all of them. And, though the themes are to some extent discrete, it will be seen that many issues arise repeatedly across the set.

These discussions are followed by conclusions and recommendations.

There is one appendix: the conceptual framework developed as part of the scoping project for the Department for Transport.

\section{Notes}

The discussion in this paper is intended to have wide application in both high-income and lowincome countries. Having said that, the bulk of the illustrations provided relate to the UK. Its quite particular characteristics are acknowledged.

The paper centres on personal transport so freight and logistics are not mentioned. Whilst there is some discussion of collective/mass transit and the potential for its automation, the majority of the paper is dedicated to travel by individuals and small groups using private modes (car, powered two-wheeler, walk, cycle etc) or taxi.

It is important to note that there is a focus in this paper upon full automation (as discussed in more detail below). Whilst partial automation is undoubtedly very important, full automation heralds profound change: the driving task can be undertaken in its entirety without the user's involvement, opening the way to vehicles travelling empty, people without driving licences making AV trips and the potential for travel time to be assigned to purposes other than driving.

\section{Preliminaries}

\section{UCL's work on AVs for the UK Department for Transport}

UCL was commissioned by the UK Department for Transport to conduct a scoping study "to identify the key social and behavioural questions associated with autonomous vehicles (AVs)". The study involved the following activities:

- A literature review

- A set of events and interviews with stakeholders both within and outside the transport sector

- Visits to and a workshop with the "four-cities trials", UK locations where major initiatives are underway to test self-driving technology with government support ${ }^{1}$

The study generated a large set of research questions that were organised into a conceptual framework (see Appendix). In addition, some specific research recommendations were made (see 
Conclusions and recommendations). The outputs of the study are currently being finalised for publication.

This paper draws on all elements of the scoping study, referring to the literature that was reviewed and reflecting the set of questions and comments raised by stakeholders. It goes beyond the study by developing further some questions that were initially posed in embryonic terms and by drawing findings together under the specific theme of governance. The views expressed in this paper are those of the authors and do not represent the opinions of the Department for Transport.

\section{A note on terms}

This section sets out some essential concepts and terms used to describe them in the remainder of the paper.

In this report, the term automation is used to describe the extent to which a vehicle is equipped to carry out the driving task, and full automation implies that the vehicle can carry out all aspects of the driving task in any environment (thus being equivalent to SAE's Level Five) (SAE International 2016).

Autonomy describes the extent to which a vehicle "makes decisions" on its own. A fully autonomous vehicle assesses its environment and selects a course of action in accordance with what it finds. In principle, an autonomous vehicle could carry out the driving task in its entirety without communicating with other vehicles or roadside infrastructure. Autonomy is here contrasted with control: a fully controlled vehicle in effect acts out instructions set outside it. One example of a high level of control is a following lorry in a platoon: it has a high level of automation, in that it does not depend upon a human driver inside the vehicle, but its movements are largely determined by the leading vehicle and so it is controlled rather than autonomous. The concept of co-operation can be seen as lying between autonomy and control on this axis: a co-operative vehicle negotiates with other vehicles and/or infrastructure in calculating its path.

A fourth concept is connectedness. This relates to the extent to which a vehicle communicates with other vehicles and/or road-side infrastructure. In order to be controlled, a vehicle must be highly connected (so as to receive instructions in real time). But a highly connected vehicle need not have any level of automation: it may simply have extensive data-sharing arrangements such as those that enable a human driver to remain very well informed about traffic conditions ahead, for example. 
Figure 1. Automation, autonomy, control, connectedness

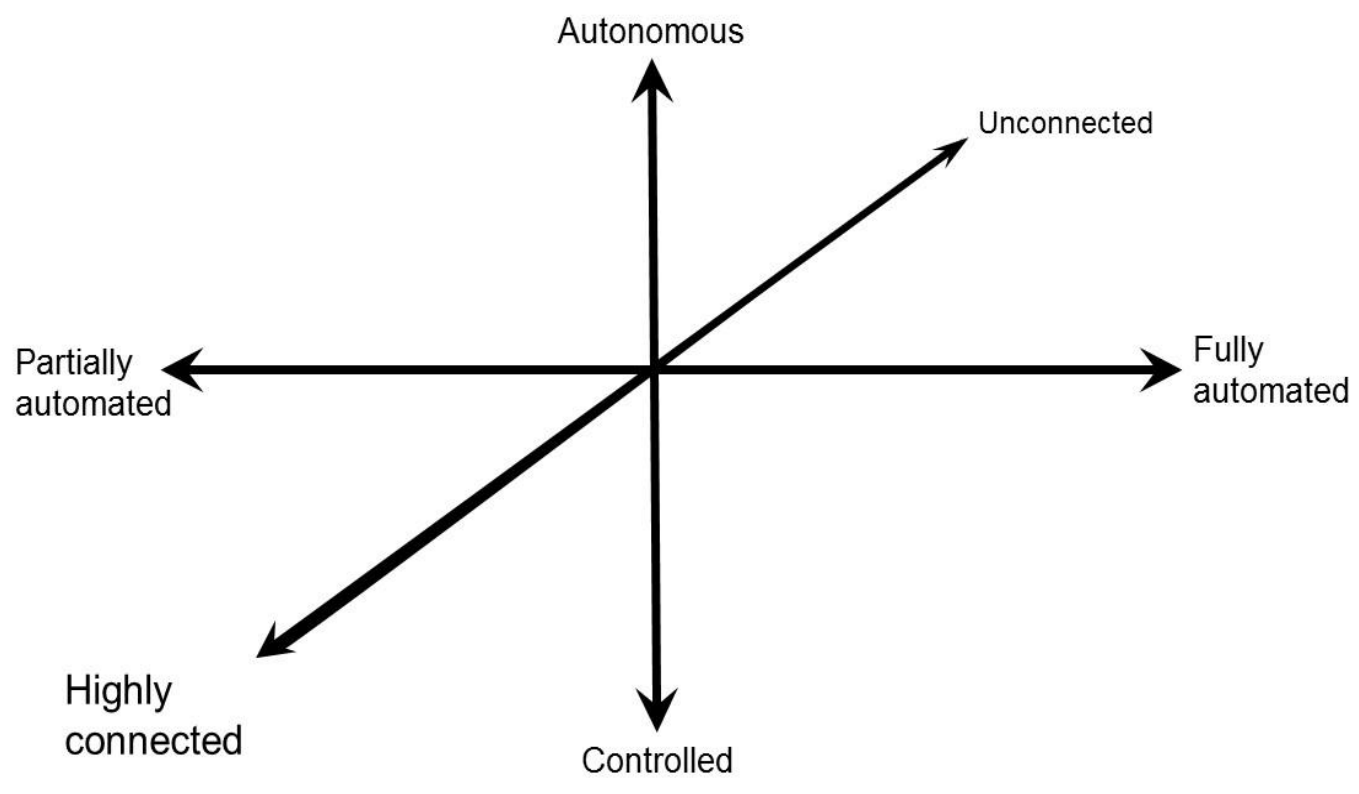

As Figure 1 is intended to show, automation, autonomy/control and connectedness are distinct axes and different vehicles will occupy quite different points on the graph. In the remainder of this paper, there is a general emphasis upon full automation so, unless otherwise specified, "AV" should be taken to mean a fully automated vehicle. Unless a point or range on the autonomy-control axis or connectedness axis is specified, the reader should assume the text refers to any point on those axes.

Though these clarifications will hopefully be useful, it must be pointed out that they alone cannot capture adequately the experience of travelling in an AV. There is a great difference, for example, between a journey in a fully automated "pod" which will not exceed $15 \mathrm{mph}$, say, and in a partially automated conventional car at motorway speeds. Where appropriate, therefore, additional information about the nature of the travel experience will be specified. Where it is not, it should be assumed that the speed and comfort of a hypothetical AV journey are at least comparable with those of journeys made currently using motorised transport.

\section{Possible models of ownership and use}

The possible models of ownership and use associated with the adoption of AVs could have a range of outcomes and societal implications which need to be further understood and anticipated. Questions such as "how will AVs be used and in what context?" and "what impact would these different "roll-out and use scenarios' have on issues such as modal share or energy consumption?" should be carefully addressed. These different 'roll-out' and use scenarios could have a profound influence on transport systems and lead to wider societal change. 
Although different roll-out and use scenarios have been described in the literature, there seems to be a broad consensus that two are likely to emerge - independently or in parallel: on the one hand, the "business-as-usual" scenario and on the other hand the "shared mobility" scenario.

The "business-as-usual" scenario has been described as a continuation of current transport ownership and use models, as experienced in most Western countries, where surface transport is dominated by the use of privately owned vehicles. Under this scenario, owners of conventional cars would gradually replace them with AVs. On the other hand, the "shared mobility" scenario describes the use of AVs in the context of emerging shared mobility trends, where vehicles are used by multiple individuals. Alternative scenarios could also develop, such as a combination of the two main scenarios; this section explores each in turn.

\section{Business-as-usual or "evolution" scenario}

This scenario implies gradually replacing all but a small minority of manually driven vehicles with AVs. It seems to be the model supported by conventional Original Equipment Manufacturers (OEMs). Indeed, most automotive manufacturers have been integrating advanced driver assistance systems (ADAS) into their products - such as automated braking or traffic jam assist - paving the way towards highly automated vehicles. More recently, global OEMs appear to have embarked on a race to producing and commercialising the first highly automated vehicles. At the beginning of 2016, in a series of similar announcements, Volkswagen's CEO proclaimed that the group "will be investing with the aim of bringing these technologies to market faster than the competition" (Horrell 2016). A number of national governments and other institutions in Western countries have been supporting this trend and view it as a commercial opportunity to foster vehicle production on an industrial scale (KPMG \& SMMT 2015; Department for Transport 2015).

The impact this scenario would have on car travel demand has been widely discussed. At best, privately owned motorised vehicles would retain their share of the market (Ticoll 2015) and car use demand would remain stable. But a number of authors have raised the possibility that fully automated vehicles could prove to be increasingly popular, leading to increased demand for car use. This hypothesis is based on the assumption that a range of non-drivers, such as young, older or disabled people, previously unable to drive a vehicle themselves, might want to start using AVs (Fagnant and Kockelman 2015; McKinsey 2015; Ticoll 2015). In the USA non-drivers are estimated to represent more than $30 \%$ of the population or circa 96 million individuals (Smith 2012). Thus, in the long-term, a large proportion of the population might start using motorised vehicles, thereby increasing levels of car ownership and use.

Furthermore, demand for car use could also increase if new technological tools associated with AVs prove to have wide appeal. Potential new users could be attracted by "moving computers" and the range of digital activities and entertainment on offer inside vehicles (Begg 2014; Fraedrich et al. 2015). AV users might be able to use AVs as "moving offices" in which to work (Bierstedt 2014; Wagner et al. 2014). As stated by Le Vine and Polak: "it may reasonably be surmised that technology that makes it easier to move about by car will serve to stimulate its use" (Le Vine and Polak 2014 p.8).

The potential impact this evolution would have on modal share has been widely discussed in the literature and has been identified as a source of concern by many. Should AVs become popular, other modes of transport, such as public transport could be negatively affected (Clark et al. 2016; Wolmar 2016; Ticoll 2015; Guerra 2015; Wadud et al. 2016). For this to happen, the price of using AVs must be competitive and the roads must remain relatively smooth-flowing. This second point is important because an extensive transfer from mass transit implies an increase in the number of vehicle-km, first, as the average size of vehicle diminishes as a result of the move away from buses and, second, as journeys transfer from metros and other forms of transit that do not operate on the road. If mass transit survived 
this revolution, it may do so as a "distressed purchase" for those with most limited means, though this may not prove a sustainable business model in the longer term without significant subsidy. As Le Vine and Polak put it: "there is a risk that [public transport] finds it increasingly difficult to compete with private car use" (Le Vine and Polak, 2014 p13). Mass AV use is likely to affect negatively the rail sector, both the freight and passenger markets, possibly rendering projects such as HS2 in the UK redundant (KPMG and Center for Automotive Research 2012). Similarly, should AV use become convenient and popular in urban areas, there could be a decrease in walking and/or cycling.

All of this could generate a renewed interest in car use and potentially car ownership, and lead to the "renaissance of the private car", as described by Thomopoulos and Givoni (2015 p.8). As Schwanen puts it: "The continuing dominance of the privately owned internal combustion engine, the neutralising absorption of car sharing by the car industry and the current enthusiasm over automated cars are reinterpreted as manifestations of automobility's capacity to endure through adaptation and influence over its environment. The socio-spatial inequalities and injustices associated with automobility are likely to persist through change as well" (2016 p.1). These "unfavourable scenarios" would, according to a report commissioned by the EU's Directorate General for Internal Policies "end in spurring private transport demand and the negative externalities related thereto" (Frisoni et al. 2016 p.14).

Should the advent of AVs lead to an increase in car use and ownership and a decrease in use of other modes of transport, such as public transport and active modes, this would generate a range of undesirable and potentially very serious consequences. Here two of the potential outcomes that have been most frequently mentioned in the literature will briefly be discussed: the impact on traffic flow and congestion and the potential impact on energy consumption.

Even though fully automated vehicles have the potential to improve traffic flow in principle, an increase in car use will mean increased vehicle kilometres travelled (VKT). Several researchers have warned that, should AVs become highly popular, the likely increase in VKT could in turn lead to increased congestion (Wadud et al. 2016; Clark et al. 2016a \& 2016b; Anderson et al. 2014; Brown 2016; Smith 2012; Begg 2014). As Bierstedt et al. put it:

"Improved driver experience and the availability of robo-chauffering for those who would otherwise not be permitted to drive may increase VKT per capita as much as $35 \%$, off-setting much of the efficiency gain" (Bierstedt et al. 2014 p.4).

That AVs will become more popular is not guaranteed, however. The likely cost of using them is currently unknown and the true operating speed remains a matter of speculation, based on degree of segregation and rules of engagement with other road users, points revisited below.

Moreover, the potential improvements in traffic flow are primarily associated with a scenario of high AV penetration rates where manually driven vehicles have been phased out of the highway and replaced by self-driving vehicles. This long-term vision should not hide the fact that fully automated vehicles and manually driven vehicles are likely to share the roads for decades, implying that improvements in traffic flow may be slow to emerge. Furthermore, in urban areas AV traffic flow might be affected negatively by AVs' interactions with other road users such as pedestrians or cyclists.

Increased VKT and congestion would have negative effects in terms of energy consumption and the environment. Even though fully automated AVs have the potential to decrease average energy consumption and emissions in comparison with contemporary vehicles, especially if supported by vehicle-to-vehicle and/or vehicle-to-infrastructure communication (Wadud et al. 2016; Begg 2014), those benefits could be off-set by a sharp increase in VKT and congestion (Anderson et al. 2014; International Transport Forum 2015). This scenario "would have large total energy and carbon implications" (Wadud et al. 2016 p.2). According to Fagnant and Kockelman, this scenario might lead to "increased emissions, greater gasoline consumption and oil dependence" (Fagnant and Kockelman 2015 p.171). The dependence on oil could worsen should AVs rely on fossil fuel, a plausible scenario if AV users expect 
to drive long distances in their vehicles (unless battery technology makes very significant strides). This range of possible impacts is summarised by Clark et al.:

"[One vision is] 'business-as-usual' with road transport remaining an essentially private 'owneruser' set of practices, with more cars and traffic resulting from the removal of constraints on who can use vehicles and when. Few vehicles are electric as purchasers must still choose a single vehicle for all likely household journey needs, including occasional long-range trips. In this context congestion, energy consumption and emissions are likely to rise due to demand growth outstripping supply efficiency. Greater physical inactivity would be a potentially growing problem for public health" (Clark et al. 2016a, p.10).

\section{Shared mobility or "collective efficiency" scenario}

AVs could be deployed and used in the context of emerging mobility models, in particular shared mobility. This new mobility paradigm is envisaged primarily as being developed in urban areas where AVs could be integrated into, and potentially complement, existing mobility systems. Under the shared mobility scenario, on-demand shared-use ${ }^{2}$ AVs, sometimes called "automated taxi systems" or "automated personal rapid transit" would offer door-to-door services to customers. The size and the shape of the vehicles would vary depending on the demand and they could be used either privately or by more than one user group at a time (ride-sharing). These systems could be particularly attractive for the "last mile" of a user's journey (Choromanski et al. 2013; Chebbi et al. 2014; Lowson 2011; Cepolina et al. 2011). It is expected that these vehicles would be used via smart connected devices (e.g. smart phones) and that companies such as Uber would drive the market. In some contexts, the vehicles could also be used by public authorities to complement existing collective transport systems.

Many authors claim this scenario could lead to "collective efficiency" (compared to the business-asusual scenario), a decline in car ownership and an optimisation of public transport and freight. Alessandrini and colleagues, who led the CityMobil project, describe their preferred future, in which the benefits of using AVs will be generated through shared mobility scenarios:

"The aim [of CityMobil] is to develop a revolutionary vision based on automated collective public transport, automated vehicles for urban freight distribution, and a shift of paradigm, consisting in the decline of car ownership and the rise of purchase of mobility services" (Alessandrini et al. 2015 p.146).

There is a difference, though, between AVs being well suited to this application and it being probable. Considering a journey between London and Edinburgh, say, there may be several arguments in favour of covering the vast majority of the journey in a train; the consumer, however, may feel no desire to interchange twice or to share space with strangers on public transport. This dilemma may be resolved in time by a technological advance that enables AVs to "couple" and travel together but this suggests a significant change for public transport: could such chains of AVs use the railway, for example? Assuming AVs remain independent vehicles, the creation of dedicated spaces for AVs on motorways may make a door-to-door journey by AV from London to Edinburgh competitive. To discourage this, it may be necessary to institute a charging framework that makes long-distance travel by AV unattractive. This might be justified on the grounds of environmental impact but it is not obvious that a congestionbased argument would be viable: if the motorways become too crowded, why should long-distance travel be singled out for "punishment"?

In urban areas, the attractiveness of on-demand, door-to-door, private or collective mobility is likely to lead to a decrease in the numbers of privately owned cars, potentially changing ownership models (Frisoni et al. 2016; Ticoll 2015; Le Vine and Polak 2014). This trend could contribute to increased efficiency of the road transport network by reducing the number of vehicles, passengers and goods on the road (Fagnant and Kockelman 2014; Ballantyne et al. 2014; Lam et al. 2014; Schoettle and Sivak 2015). Shared AV mobility systems would be particularly effective if vehicles employed vehicle-to-vehicle 
and/or vehicle-to-infrastructure communication and were integrated with existing mobility and public transport systems (Alessandrini et al. 2014 \& 2015). A decrease in car ownership and a more efficient network could bring a range of positive outcomes such as freeing parking space. For these reasons, various authors see this as preferable to the business-as-usual scenario. As Thomopoulos and Givoni (2015) put it: "A change where public and sharing will be seen as superior to private and individual transport, could make the automated car a blessing" (p.1) and provide an opportunity to "de-privatise car use" (p.2).

Even though some argue that this scenario has the potential to decrease congestion and tailpipe emissions (providing all AVs are zero-emission), should AV use become extremely popular and convenient, it could still lead to an increase in car travel. "Users that would typically take transit may switch to shared automated vehicles if they are significantly more convenient at a comparable price. This may cause transit to be starved of ridership, resulting in lower cost recovery of transit infrastructure, and eventually reduction of services or increases in fares, both of which will perpetuate loss of users to AVs" (Frisoni et al. 2016 p.83). As identified under the business-as-usual scenario, should AVs become more popular than other modes of transport, such as public transport or rail, it could lead to a decline of those services (Enoch 2015; Fagnant and Kockelman, 2015).

Therefore, it is argued that even under a shared mobility scenario there will be a need to anticipate shifts away from public transport/active modes and to manage demand. The optimal solution would be to ensure that on-demand AV systems are as integrated as possible into existing mobility systems, including incentives to promote ongoing use of mass transit. This should ensure that AV use does not lead to increased congestion and other unwanted consequences such as a decrease in physical activity. The alternative, as Begg sees it, is gridlock if AVs prove very popular in London: "it is essential to maintain the modal shift away from car if mobility and accessibility are to be maintained" (Begg 2014, p.34).

\section{Automated collective transport combined with on-demand shared AVs}

In some countries, such as Singapore, public authorities are planning to automatise their collective transport systems and to use on-demand AVs to complement a broader automated mobility network. Some believe the combination between automated public transport and on-demand shared-use AVs has the potential to optimise a city's transport network (Benmimou et al. 2009; Aoki 2004; Clerget et al. 2004; Alessandrini et al. 2015). Examining the case of London, Begg argues that automation and connectivity could enable the bus network to operate more rapidly and efficiently and that on-demand AV "pods" could usefully complement public transport in low-demand areas of the city (Begg 2014). The Singapore model consists of exploiting this new technological tool to improve transport systems. Thus, automation could optimise public transport systems and, if carefully integrated, on-demand shareduse AVs could complement existing transport networks.

\section{Parallel deployments}

The "evolution" and the "shared mobility" scenarios described above could of course develop in parallel. Certain conventional vehicle manufacturers are already teaming up with shared mobility companies to launch automated taxi services in addition to their effort to develop privately owned AVs. For instance, General Motors has announced that it will be collaborating with the E-hailing ${ }^{4}$ company Lyft to create automated shared taxis (Ramsey \& Nagesh 2016). This model is being replicated by other major OEMs, for instance with the collaboration between Uber and Volvo, in a "battle to reshape the auto industry" (Ibid). 


\section{Conclusions}

Under both of the two main scenarios described above, VKT could increase, possibly leading to a range of unwanted and undesirable consequences such as increased congestion, energy consumption and emissions. According to Fagnant and Kockelman, the first two AV-use scenarios are moving towards: "more vehicle-miles travelled... and automobile-oriented development" (Fagnant and Kockelman 2015 p.170).

Public authorities in most countries will be presented with different governance choices vis-à-vis AVs. One of these choices will be to let the market develop AVs and accommodate this new technology and the subsequent demand for AV use. Another policy route would consist of making some anticipatory choices to accompany and steer the development of AVs towards desired policy and societal objectives. The latter is more likely to prevent unwanted consequences associated with increased car use. As Howard and Dai conclude: "How we choose to implement this technology will make the difference, and that largely depends on the views of political and market actors" (Howard and Dai 2013, p.17). A transition towards vehicle automation could make transport systems more efficient and improve road safety, if public authorities and other stakeholders act to ensure this. As models such as Singapore suggest, the careful integration of this new technology into existing transport systems could lead to gains in both personal accessibility and operational efficiency.

\section{Potential strengths and weaknesses of different operating environments and regimes}

In the previous section, possible futures involving $A V s$ have been introduced from the perspective of user and policy response. Here the discussion turns to the environment in which AVs may be used. In particular, is it possible to predict on what types of road and in which locations AVs might offer most benefits? A better understanding of this may help to inform the development of policy relating to AVs.

\section{Varieties of road}

Any discussion of the potential for and potential impacts of automated vehicles must take account of the existing wide variation across roads. In terms of infrastructure, roads differ in width, number and type of lanes, curvature, frequency and nature of junctions, whether dual or single carriageway, whether parking is permitted and so on. They also range in nature of surface and its condition as well as the condition of markings and signage. These sets of characteristics help to determine a road's operating speed and any prevailing speed limit.

Then there is the road's environment: some roads are effectively secluded whilst others are located in areas of intense activity. And there is the traffic they carry and the degree to which this is actively managed. On a very large proportion of the world's roads, there is no strict delineation of space between pedestrians and those travelling in vehicles, for example. On a small proportion, certain types of travel or vehicle are excluded.

As the prospect of automated vehicles is contemplated, the varied nature of the highway network must be actively confronted: it is clear that, at least to begin with, AVs are likely to perform better in some environments than others. 


\section{More and less promising environments}

It is no surprise that motorways have already been identified in the UK as suitable environments for partially automated vehicles: the forthcoming Modern Transport Bill in the UK is intended to make lawful certain advanced "driver assist" features on motorways (Centre for Connected and Autonomous Vehicles 2016). ${ }^{5}$ Motorways have several features that mark them out as suitable testing grounds for AVs: they are partially segregated, in that neither pedestrians nor cyclists are permitted to use them, and there is no building frontage; they have simple junctions, involving merge/diverge conflict as opposed to crossing conflict; they are dual carriageways such that all movement on a given carriageway is in a single direction; they have wide lanes; all turns are gentle; and they tend to be in good condition. All of these could be seen as making motorways "simple" environments to navigate and therefore a suitable setting for the testing and development of automated technology.

This raises the question of whether this simplicity makes motorways merely a suitable starting point or whether automated vehicles will always fare better on such roads, even as the technology develops. On the one hand, advances in self-driving hardware and software can be expected to enable an increasing range of environments and scenarios to become manageable by AVs. On the other, complex scenarios will continue to be complex. Human drivers typically manage this complexity by slowing down and it is likely that AVs will have to negotiate complex situations more slowly than they do simple ones. This may pose no problem, unless it jeopardises the claims that AVs will bring significant increases to the safety and/or practical capacity of the highway network.

On the theme of safety, would greater gains be expected on a motorway than on an urban street? Motorways are already considerably safer than urban roads (per vehicle-kilometre) (Department for Transport et al. 2015, p.84). If AVs are able to eliminate a consistent proportion of crashes across highway environments, this indicates that they will have more to offer on urban streets than motorways. But this seems unlikely: the human error that is often cited as lying behind $90 \%$ of crashes (Smiley and Brookhuis 1987) takes different forms. Loss of concentration is not the same as a failure to judge a situation correctly. Current technology seems much better suited to assisting with the former than the latter, ${ }^{6}$ again pointing to the motorway as a more promising environment.

In terms of practical capacity, headways (minimum gaps between vehicles) and lane widths on motorways could both presumably be reduced with the arrival of AVs. The first should increase the capacity of each lane and the second may enable the creation of an additional running lane. Furthermore, if the expected reduction in crashes came about, it seems very likely that a case would be made for increasing the speed limit. If this were granted, further capacity increases may follow. ${ }^{7}$

Turning to the urban environment, some of the same arguments apply: junction capacities would be expected to increase because of reduced headways; large quantities of highway space currently given over to parking would be released (Frisoni et al. 2016; Fagnant and Kockelman 2015; Anderson et al. 2014), possibly for use as additional running lanes (discussed further below).

But all of these assertions concerning capacity are based on an assumption that fully automated vehicles will dominate and will not have to interact with other road users, including pedestrians, cyclists and users of manually driven vehicles. A segregated network for AVs may enable some of these capacity benefits to be reaped but segregation (discussed further below) seems considerably easier to deliver on a motorway than in an urban environment. Without segregation but instead in a mixed-traffic environment, most of these capacity gains cannot be expected to come about. Space may indeed be released in urban areas because of reduced need for parking. If this were converted to running lanes, it is hard to see that this would do other than cause congestion, given that junctions would have the same capacity constraints as before. Moreover, the need for AVs to avoid collisions with other road users may prove a greater impediment (Adams 2015; Le Vine and Polak 2014), a subject which is returned to below. Thus the tentative conclusion is that urban environments are less likely to experience the capacity benefits of AVs 
than motorways, in spite of their typically more pronounced current capacity problems. That is, the complexity of urban environments is likely to militate against the achievement of the capacity gains which various authors see AVs offering.

\section{Other environmental differentiators}

Having contrasted two categories of road, it is appropriate to conclude by widening the discussion to embrace spatial, cultural and economic differences across operating environments and regimes, as it is not obvious that $\mathrm{AVs}$ will become equally prevalent in all places.

First, and reflecting discussion above, some places will be more suitable environments for AVs than others. A mediaeval city built for walking and the occasional mule, such as Fez in Morocco, is no more suited to $\mathrm{AVs}^{8}$ than to conventional road vehicles (Brombacher 2014; Young and Rudin-Brown 2014). Extending this argument from the extreme case of an Arab medina, a sparsely developed settlement with wide roads and infrequent junctions (such as many north American cities) seems a more natural place for AVs than a city with a dense network of narrow roads, and AVs may therefore prove more popular in the former (Alessandrini et al. 2014). Second, culture is likely to play a part, with a community's enthusiasm for automation combining with its general fondness for cars and driving to determine the likely reception of the technology. For example, Bansal et al. (2016) detected a preference for AV use amongst wealthy, tech-savvy males living in dense urban areas in the USA. Third, with respect to wealth, AVs may remain something for high-income countries (Urry 2013). This may be a function of individuals' abilities to afford the use of AVs but it will also reflect the fact that their use will depend on a degree of new infrastructure (McKinsey 2015; International Transport Forum 2015): whether paid for by the state or the private sector, there needs to be sufficient wealth in a nation's or region's economy for such infrastructure to be a realistic prospect.

To conclude, other than distinguishing between urban and inter-urban travel, little research on AVs differentiates in any detail between settings. The above discussion, though, clearly demonstrates that environments differ considerably both in their readiness to receive AVs and in the extent to which the benefits of AVs might be experienced. These differences are, if anything, likely to be more pronounced across "unsegregated" environments. A better understanding of these differences could inform a rich analysis of the relationship between potential benefits of AVs and the distribution of transport need, thereby informing policy. This theme is returned to below in the discussion of seeking an optimum. 


\section{How automated vehicles might integrate with/modify the existing transport mix}

Discussion now turns to the impacts of AVs upon other road users and the consequent effects on the functioning of the network.

Many of the predictions concerning the impacts of AVs assume (implicitly or explicitly) $100 \%$ penetration of fully automated vehicles. At this point, all the safety and efficiency benefits will be realised and passengers will not need to give any attention to the driving task, so may be able to work, socialise etc. This picture does not explain the place of non-motorised road users, which will be discussed further below. But, as a traffic management scenario, it seems straightforward, provided all issues of shared standards and algorithms have been resolved. At the other end of the spectrum is the point at which the first fully automated vehicle enters the traffic stream. Because this vehicle will be the anomaly, it seems obvious that it will have to comply with the norms of the majority. The matter is slightly more complicated because its sensors and safety features might make it liable to stop more readily than manually driven cars. But, in broader terms, there is no expectation that a segregated lane will be provided for the first AV.

Rather more interesting are the points in between, when AVs represent $25 \%$ of the fleet, or $75 \%$, say. This can be helpfully illustrated by reflecting on the emergence of "horseless carriages". When they first arrived on the streets, drivers were expected to fit in with the prevailing practices of the time as determined by the dominant form of transport (apart from walking) - horses. In fact, this expectation was backed up by law: the UK Locomotive Act 1865 introduced speed limits of $2 \mathrm{mph}$ in cities and $4 \mathrm{mph}$ in the countryside and required certain motorised vehicles to be preceded by a person walking with a red flag (The Society for the Diffusion of Useful Knowledge, 1866). Though this latter aspect is often raised humorously, the underlying serious point is important: whilst a technology is used by a small minority, they will be expected to comply with prevailing norms. And the fact that the Locomotive Act was repealed some years later (when the number of automobiles had increased) demonstrates that a tipping point can be reached. The change in the law reflected an acceptance that traffic norms needed to alter in light of the new shape of the "fleet". Horses are still allowed on most British roads today but the roads are not designed or operated with them in mind and they are not allowed on motorways, the "elite" form of highway infrastructure.

It seems likely that such a tipping point will be reached with AVs. When they first emerge, no concessions will be made and it seems that few traffic benefits will result. When their number reaches a certain point, it can be expected that their users will argue for changes to the highway regime. But what changes? The answers may lie mainly in two areas: allocation of space and traffic rules. With respect to the first, segregation of traffic types has been identified above as an obvious way of allowing AVs to deliver some of their promised benefits in terms of capacity. Without segregation, AVs may be able to provide a safety improvement over other types of vehicle but at the cost of operating in accordance with the lowest common denominator (Fagnant and Kockelman 2015). This is because, at least for now, the safety claim is sacrosanct and so it is not possible to speak of there being limits on the extent to which AVs allow for the behaviour of others (Le Vine and Polak 2014).

Suppose, for example, that an AV is travelling on an open road at $40 \mathrm{mph}$. It is able to do this because there are no other road users (nor anyone who could enter the highway) within 500 metres. As it advances, a cyclist is detected. Current assumptions concerning the protection of all road users imply that the AV will slow down gradually as the distance between the two decreases and, as the two pass each other, it will be travelling sufficiently slowly that it will be able to stop safely or take safe evasive action in response to anything the cyclist might do. It is easy to see that, in an urban mixed-traffic environment, 
AVs will need to travel at this minimal speed most of the time. But it seems unlikely that this will constitute a satisfactory situation and Le Vine and Polak (2014) suggest some safety compromises are therefore very likely.

Segregation would offer a natural alternative: if a closed system is created in which all vehicles are operating according to a shared set of rules, there is no need to travel at extremely low speeds and the AV proposition becomes more attractive to potential users. This suggestion should not be made lightly, though: the scope for segregation is a function of the highway environment: in some places, it will be possible to create an AV "lane" whilst still providing for other road users. Elsewhere, there will be space for only one category of traffic, implying that policy makers will have to choose the "winner". At present, it seems obvious that "other road users" would be preferred but it would be short-sighted to assume this will always be the case. As for segregation, it will probably be impossible to prevent completely the intrusion of trespassers onto the AV lane. This may imply that the so-far sweeping safety claims relating to AVs will become more nuanced: AVs will be designed to protect the welfare of all road users, including those who may be feckless, but they perhaps will not be expected to protect those who wilfully enter an area dedicated to AVs.

This leads to a wider discussion of traffic rules. The status quo is a set of norms and laws that demand road users take sufficient care within an environment where mortal harm is a genuine risk. Implicit is the understanding that a reckless act on a user's part is treated accordingly - as reckless and therefore culpable. A person who wilfully throws themselves in front of a fast-moving vehicle is considered the guilty party. Current attitudes are subtler with respect to actions that do not constitute "normal" behaviour but are not reckless either: the pedestrian who, walking at the edge of the footway, trips on a paving slab, falls into the carriageway and is struck by a car, for example. The general view is that, if "there was nothing the driver could do", no fault is to be assigned. But what if there was something the driver could have done? AVs are generally predicted to have quicker reaction times than human drivers so the range of feasible evasive action will be wider and expectations may expand accordingly. This suggests that the line between vehicle culpability and blamelessness may lie in a different location than it does for human drivers. But it seems very likely that, in an environment involving a substantial number of AVs, there will be such a line and society will not expect AVs never to be involved in collisions. ${ }^{9}$ It is then a matter of translating such principles into the algorithms that determine the vehicles' behaviour. Writing algorithms that take the right amount of care will not be a trivial exercise - enough to protect road users as far as possible, but not so much as to make the mode uselessly slow. But the more significant point is that blanket guarantees of AVs protecting all life in all circumstances are unworkable.

Whether or not these changes come about, it remains unclear what level of AV uptake is likely. This is illustrated using a highly simplified causal loop diagram (Figure 2). As demand for AVs rises, traffic volumes increase, leading (in urban areas) to reduced average traffic speed, which in turn diminishes demand for AVs. ${ }^{10}$ But what cannot be known at present is the relative strength of the relationships and whether a new "equilibrium" would be a highly congested network or one where, as at present in London, the various costs of using a private car in congested conditions act to nudge people onto other modes. 


\section{Figure 2. Traffic causal loop diagram}

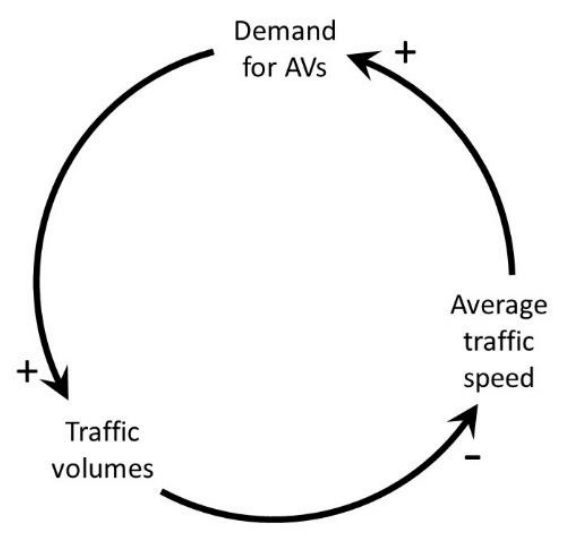

The above discussion provides good reason to expect that fully automated vehicles would bring major change to the network, though that change may not come about until the number of AVs reached a tipping point. But any change is contingent upon various factors that will determine how attractive a proposition AVs are, most significantly the way the network operates and the volume of road traffic. There is likely to be a dynamic relationship between these two - the more AVs are in use, the greater will be the pressure to adapt the network to suit them - so it is not possible to say at present where any future "equilibrium" between supply and demand might lie. But it is very clear that public authorities at all levels have very considerable power to influence these developments. Having raised this in a number of specific contexts, a wider discussion of the role of public authorities now follows.

\section{Possible consequences of "laissez faire" or more directive governance}

"Whether the AV locks us further in or out of the 'car based society' depends on the choices we make as a society, not solely on a specific technological development" (Thomopoulos and Givoni 2015, p9).

The choices "we make as a society" are slightly ill-defined but it is unarguable that, whatever they are, they are very much influenced by prevailing public policy which is, in turn, very much influenced by the attitudes of society's members. In this section, the range of potential public-sector intervention is explored and assessed from the perspective of attempting to determine what level of governance may be most desirable.

\section{The potential and actual range of public-sector intervention}

Governments at both a national and a local level already intervene to a great extent in transport in general and in road transport in particular. The following list sets out some of the areas of current intervention:

- Which vehicles can use which roads and when (e.g. pedestrianisation, restrictions on which vehicles are permitted on motorways, time limits on deliveries, roads closed to heavy vehicles) 
- Conduct on the road (e.g. speed limits, obeying red/green signals, freedom to park)

- Driver and vehicle (e.g. qualifications to drive, vehicle condition and functioning, requirement to insure)

- Safety equipment (e.g. helmets for riders of powered two-wheelers, lights on vehicles)

- $\quad$ Cost (e.g. fare regulation, road pricing, fuel duty)

- The nature of highway infrastructure and/or rules governing its operation

This list naturally reflects the long history of mixed traffic including the long-standing presence of manually driven road vehicles. The scope of intervention does, however, alter over time. For example, sensing equipment is a novel addition: recent regulations relating to Advanced Emergency Braking Systems (AEBS) include stipulations concerning a vehicle's capacity to detect an obstacle (European Commission 2012). Currently absent are regulations relating to the management of "trolley problems", 11 though it seems inevitable that they will appear in due course. Also currently absent are any regulations concerning who may make which type of journeys and at what times. This second example may appear well beyond the remit of public authorities with respect to transport but it has some relevance, as discussed below.

The development of public-sector intervention with respect to road transport can be characterised as gradualist - regulation or other action occurs in response to a development that is perceived to necessitate it. The advent of automation has prompted some to argue for a more active stance (Enoch 2015; Thomopoulos and Givoni 2015; Begg 2014), the International Transport Forum (2015) seeing a lack of evidence that government is preparing sufficiently, and Clark et al. (2016b) calling for government leadership.

What public bodies can do and whether their action would prove beneficial overall is now explored through a set of topics:

- Demand management;

- Released space;

- Market failure; and

- Crime and justice.

\section{Demand management}

This topic recalls points made above concerning whether claims of increased highway capacity will come to pass. This can be illustrated by contrasting control with autonomy. It is almost certain that, left to its own devices, the market will deliver autonomous vehicles, being AVs that assess their surroundings and proceed in a way that is optimal for the individual user(s). The problem with this is a familiar one in transport terms - a large set of individuals making decisions that are individually optimal will generally produce an aggregate situation that is sub-optimal (Heydecker 2016), the most obvious consequence being congestion. And it has been suggested that AVs may prove a victim of their own success, roads becoming clogged by users trying to enjoy new-found freedoms (Wadud et al. 2016; Clark et al. 2016a \& 2016b; Anderson et al. 2014; Brown 2016; Smith 2012; Begg 2014). 
The converse of autonomy is control. In a fully controlled network, each user would submit their journey desires to a central "control system" which would weigh up the collective requests and seek an optimum. ${ }^{12}$ Each vehicle would then receive its "flight path" which may or may not coincide with the initial request. For, in order to achieve the system-level optimum, it is extremely likely that certain journeys would need to be shifted in time, given routes that are not the most direct, or even assigned an alternative (equivalent) destination. Whilst this sort of arrangement is very familiar in a range of congestible networks such as the internet (Ofcom 2016), it is far from the norm in road transport where the tradition has always been that people can, within reason, travel at will. And it would constitute a very major departure from the pattern of public-sector intervention to date.

As described above, such a scenario seems implausible, especially if, in a mixed-traffic environment, those in charge of other types of vehicle would be able to carry on as before. Co-operation may offer a more palatable second-best. Here, vehicles would, through communication with each other and road-side infrastructure, obtain information about conditions on the network and be able to plan accordingly, perhaps agreeing with other vehicles to spread demand. This scenario would have the advantage of enabling vehicles to avoid the site of a collision, say, but would be unlikely to match the performance of the fully controlled network.

Recalling an earlier point about the future of mass transit, its survival may rely on a degree of public intervention to support the integration of AVs with the public transport network (Alessandrini et al. 2014 $\&$ 2015). In the absence of central control, this would have to mean some form(s) of incentives that in certain circumstances made a journey combining AV with (classical) public transport attractive, relative to travelling by AV alone.

Of the incentives available, pricing is perhaps the most familiar, though it is likely to be less effective than control, given individuals' varying response to financial stimuli. Here, however, there is a precedent, with various congestion-charging schemes in operation around the world, designed to guide demand towards a social optimum. AVs offer the means to introduce smart pricing (since it is generally accepted that they will be fitted with tracking equipment) and this may help to make pricing more publicly acceptable than hitherto. Perhaps more significant is the possibility of "bundling" charging with the new technology: ensuring that the arrival of full automation is firmly combined with pricing such that there does not need to be a future point when pricing is introduced after a period of driving AVs "for free". Whether this will alter popular attitudes towards road pricing is moot. Again, if pricing is proposed for AVs whilst other road users carry on as before, this seems unlikely to find favour unless the AVs are operating in a "premium" environment such as a segregated network would provide. In the UK, for example, the M6 Toll (a section of tolled motorway north of Birmingham) does not excite the controversy of congestion charging because there remains an alternative high-speed route that is free at the point of use. Users can choose to pay for a more reliable journey or take their chances with the cheaper option. In a shared-use scenario, pricing appears plausible, not least because many users of public transport are familiar with the notion of paying more to travel during times of peak demand, but also because users are likely to pay "per trip" rather than buying the vehicle and its consumables up front. The road pricing element could be combined with the base cost of the trip, thereby drawing less attention to it.

The above discussion has been based on the assumption that expectations will remain largely as they are now and most writing on AVs reflects an implicit (or explicit) assumption that use of AVs will evolve from contemporary car driving, implying an expectation that current freedom of choice will be preserved. So it is worth mentioning the idea of a culture change. Users of public transport are inured to accepting the routes and timetables set by operators and they plan their travel accordingly. It is possible that AVs will partially acquire the character of public transport: users may not so much expect to be taken immediately to their destination by the most direct route as instead accept that their initial travel desires will be "translated", perhaps with some modification, into the journey they actually make. And 
this may seem an acceptable price to pay in exchange for door-to-door convenience, and certainty. Reflecting on the discussion of models of ownership/use above, this readiness to accept modifications seems likelier to accompany a shared-use model than an owner-user model, thus providing further evidence in favour of the former.

\section{Released space}

A second area of potential public-sector intervention is space for parking. As discussed earlier, in a scenario of fully automated AVs being used predominantly on a shared basis, it should no longer be necessary for vehicles to spend long periods parked (Clark et al. 2016a; Frisoni et al. 2016; Fagnant and Kockelman 2015; Anderson et al., 2014). Even with an owner-user model, AVs should be able to move away from urban centres during periods when they are not needed. Given that a great deal of the land on which vehicles are currently parked is publicly owned, what will authorities do if it is no longer needed for parking?

The land's location, typically between footway and running lanes, limits the options for reallocation. Alessandrini et al. (2015) ponder its use to extend the public realm; it could equally be allocated to walking, other forms of active travel or to public transport. Another obvious use would be as a running lane for private traffic, particularly if the predictions of increased vehicle-km prove correct (Begg 2014). The possible role of the private sector should also be considered: a strip of land with high footfall (as in urban centres) is a natural retail opportunity. This presents the authority with dilemmas: whether to pursue social good directly or indirectly (by generating income that could be used to meet other needs) and, if the former, which good to pursue. The tension between movement and place is now a familiar one (Transport for London, 2015). At the time of writing, the policy climate in London is favouring health (Transport for London, 2014) and so, there at least, if the space were to be reallocated to a transport purpose, the pedestrian and cyclist would be the likely beneficiaries. But local authorities need always to protect their finances, so the revenue prospects of exploiting commercial opportunities should not be discounted too readily.

The true laissez-faire response to highway space becoming free would be to do nothing and let the users determine its future use. Though an authority is unlikely to be quite this permissive, the probable consequence would be that the space was adopted by vehicular traffic. And, of the three options discussed above, the one that most resembles this scenario is the active provision of a further running lane. Would this be a desirable development? In one sense, it would allow more people "to do what they wish" in terms of travel and there is a long history in transport policy of doing this. But, if junction capacities in urban areas remain the practical constraint upon the volume of traffic that can be accommodated, it could prove counter-productive.

\section{Market failure}

How would authorities respond to the prospect of market failure? This is not currently widely contemplated, the literature instead tending to reflect an assumption that the technology will arrive and be taken up. But this is not guaranteed: manufacturers may be wary of a development that threatens large losses through legal action, as suggested by Le Vine and Polak (2014) who cite the reluctance of pharmaceutical companies to manufacture vaccines in light of the risk of having to pay damages. Thus, fully automated cars may not reach the market. If they do, their use may be very expensive at first (Bierstedt et al. 2014) and there is a history of innovations foundering because of a lack of early uptake. If the AV market appeared to be failing, what should authorities do? The answer will presumably vary from nation to nation, reflecting both a national government's spending power and the perceived importance of the market at risk. At the moment, the UK government's stated interest in AVs lies in two categories - the commercial benefits and the transport benefits (Department for Transport, 2015). To 
what lengths could and should it go in reviving the AV market in order to capture these benefits? At the extreme end, it could shore up the relevant businesses through subsidy, perhaps even nationalising certain organisations. This has a recent precedent: on several occasions, the Department for Transport has (sometimes through holding companies) taken over rail franchises when commercial arrangements have broken down (BBC News, 2009). Whether it would act in such a way prospectively (i.e. before a technology had become a central part of the transport network) is not clear. For now, the transport benefits of AVs are not certain so it is fair to imagine that significant intervention is unlikely. This could change, of course, if a broad consensus developed that supported a more optimistic view of the potential of automation.

\section{Crime and justice}

Cybercrime is much mentioned in the literature, with several writing about the risks and the standards that public bodies will need to establish to manage them (Fagnant and Kockelman 2015; DiClemente et al. 2014; Wagner et al. 2014; International Transport Forum 2015). Supposing, though, that the only sure way of minimising the risk of a disastrous act of cyber-terrorism was to limit individual freedom, perhaps by requiring AV users to reveal their identities at all times. Would authorities require this? Taking the idea further, a security against such attacks might be to install "government override" in all vehicles. Whether this would be acceptable seems to depend on how the vehicles would be owned and used. An AV owner-user may find such an imposition harder to stomach than a more casual user, habituated to surrendering a degree of autonomy whenever boarding public transport. Nevertheless, a more interventionist authority may attempt to justify actions of this kind on the basis of public safety and may be vindicated in the long term; a more libertarian regime may opt to take the risk and may, equally, be vindicated. But the latter regime faces a higher cost if proved to have made the wrong decision.

It is helpful to explore the theme of justice through a contemporary example of a woman jailed after her child was killed as she jaywalked with him in Georgia, USA. In Balko's (2011) account, her situation is presented as deeply unjust: the "safe" means of crossing between the bus stop and her home involved an inconvenient detour; the driver who struck her son fled the scene; he had impaired vision and a history of such incidents, and admitted to having drunk and taken painkillers that evening; he served six months of a five-year jail sentence, whereas she was likely to be jailed for three years. Whether this is a balanced presentation of the facts is perhaps less important than that the writer (and, presumably, the 5200 people who signed a petition seeking a pardon for Raquel Nelson (Davis 2011)) believe the transport system (reinforced by the judicial system) to give unjust priority to the car driver over the pedestrian. Supposing this to be the case, the next question is what, if anything, authorities might do to address injustice as AVs arrive on the scene.

Bonnefon et al. (2016) conducted a survey that indicated respondents sympathised with "utilitarian" vehicle design but would choose to travel in an AV that prioritised their safety over that of others. It seems likely that manufacturers would bear this in mind when designing their vehicles. If the status quo implicitly prefers the driver of a motorised vehicle over other road users, can it be expected that AV users will automatically be propelled into an additional, higher category in the hierarchy? This recalls earlier points about the prospects for segregation: first, if parts of the highway network are reallocated to AVs, this implies that there will be less "to go around" the other users. At-grade segregation also has the important consequence of reducing the accessibility of other road users, particularly pedestrians. Returning to the case from Georgia, there would be pressure from AV users for a segregated network to be subject to as few stops as possible, in order for the benefits of segregation to be reaped. How many concessions, then, would be made to those needing to cross such carriageways? If the market were to decide, it seems likely that the AV facilities would be favoured. A more directive authority may pursue an egalitarian line, with the consequence that the AV user gained less in comparison. The general point is 
that a laissez-faire approach to the arrival of AVs is likely to consolidate any existing inequality and that deliberate action will be necessary if a different balance is to be arrived at.

\section{Discussion}

The gradualist approach of public-sector intervention in transport has been identified above and indicates that the more "exotic" regulatory opportunities that will accompany the arrival of AVs may not be grasped rapidly. Authorities are likely also to be cautious in employing policies that might be characterised as constraining freedom in any way (as with the notion of a controlled network). This suggests that laissez-faire will dominate by default and that autonomy (and not control) will therefore be the prevailing regime. A specific consequence is the persistence of congestion in a world including AVs, with all its negative consequences, though whether it will be more or less severe than at present is not possible to say. As to when authorities should act, several authors argue for the "wait and see" model in preference to regulating on the basis of hypotheses about the future (Bohm 2015; Fox 2016; Anderson et al. 2014) though many urge a more interventionist line (Anderson et al. 2014; Clark et al. 2016a; Le Vine and Polak 2014; Begg 2014).

In closing, whilst much of the above discussion suggests that authorities can act to improve the outcomes that are seen with AVs, it should not be assumed that such actions will deliver benefits that outweigh their costs. Just as leaving the market to determine the matter will create winners and losers, so will a more interventionist approach to governance. Any public authority will need to establish a strong case for action, particularly given the history of opposition to regulation in transport. A possible way forward, therefore, is to foster public debate on certain of the issues. This has already been proposed on oft-discussed trolley problems (Frisoni et al. 2016; Bonnefon et al. 2016) but it could have wider application, with the effect of providing authorities with confidence concerning both which areas most deserve action and which specific actions would be publicly acceptable.

The next section is based on the assumption that authorities will take a more interventionist line and asks what might then arise.

\section{What "optimum" might mean and challenges authorities will need to address in attempting to deliver it}

The purpose of this section is to explore the implications of setting and pursuing a single objective. Transport policy is, of course, a great deal subtler than this: there are multiple objectives, generally accompanied by constraints, and authorities are tasked with finding a workable compromise. It is therefore best to consider this section as a thought experiment intended, through its simplicity, to permit some tentative conclusions to be drawn about the likely consequences of pursuing one or other goal. Moreover, what is true of pursuing a given objective in isolation may be true of pursuing it in combination with others.

It is legitimate to begin by asking whether authorities should in fact seek to achieve an optimum. ${ }^{13}$ One response would be to ask, if it did not, what instead they would be seeking to achieve. For authorities to seek something other than the most desirable outcome would appear perverse. But pursuit of the optimum may prove unacceptably costly. Or the optimum may be unattainable, making it 
necessary for an authority to concentrate on less desirable, but attainable, goals. Before any of these issues can be addressed, though, the optimum must itself first be defined.

This is not straightforward. According to the UK Department for Transport, it is there to "keep Britain on the move" (Department for Transport n.d.). Whilst this serves in a superficial way to explain its purpose, it does not constitute an indicator against which success could be judged. The quantity to be optimised in transport instead tends to relate to speed (journeys to be made at the highest possible speed subject to suitable constraints), capacity (the network to accommodate the greatest volume of travel possible) or accessibility (users being able to reach destinations they value at an acceptable [generalised] cost). Reliability has appeared more recently (journeys to be as reliable as possible) but will always accompany another metric because high reliability will not be treasured if it comes at the cost of very low speeds. ${ }^{14}$ Externalities appear in the stated goals of transport agencies, in terms of reducing casualties, noise, emissions etc. Again, these will not be used to define an agency's mission but will act as constraints.

This degree of variation makes it difficult to be specific about a future optimum in a world of AVs. Most discussion of AVs in this context has tended to emphasise capacity increases, with little said about the prospects of AVs travelling at a higher speed than manually driven vehicles. Indeed, the UK government proposed in 2011 to increase the speed limit on motorways but set the idea aside some months later, which suggests that the policy fashion in that country is not in favour of increased speed (Gayle 2013), at least for now. It is perhaps safe, therefore, to conclude that the optimum, with or without AVs, will not be speed-related. On the basis that reliability will always be subordinate to another goal, this leaves capacity and accessibility as the strongest candidates.

If the goal were the maximisation of capacity, this would reintroduce the contrast between control and autonomy discussed earlier. A greater practical capacity can be achieved (that is, more vehicle-km can be successfully driven) if journey demands are managed than if all actors make trips at will, even with the benefit of information provided through connectivity. But it is immediately apparent that the dogged pursuit of this optimum will be politically challenging, given points made above concerning likely attitudes to a controlled system. If, as suggested, a fully controlled system is not palatable, smart road pricing would be an alternative way of "sweating the highway asset" so as to enable a greater volume of travel to take place. ${ }^{15}$ Its public acceptability is less clear but, as discussed above, an authority may be able to introduce it as "packaged" with the technology, and render it more tolerable by offering in compensation the benefits of a segregated network.

This does not address the question of whether it is desirable to maximise capacity. Seeking to accommodate as much movement as possible (which would appear to serve the Department for Transport's mission of keeping Britain on the move) implicitly characterises mobility as a good thing. An alternative goal is to reduce the need to $\operatorname{travel}^{16}$ which reflects a more qualified assessment of mobility, as not intrinsically desirable. These contrasting positions predate the advent of self-driving technology by many decades so the prospect of a transport revolution (in the form of self-driving technology) merely prompts a re-examination of a familiar debate. If movement is a good thing and if AVs will enable more movement to take place, it follows that more movement should take place, though this may be at the expense of increased energy use and, quite possibly, greenhouse gas emissions (Wadud et al. 2016). Reflecting on the earlier discussion of how to allocate space previously used for parking, the principle that "movement is good" appears to imply that such space should be dedicated to movement rather than place.

Turning now to accessibility, this is an attribute that varies over people and locations so optimising it is not a simple matter of seeking its maximum value. There is an extensive literature on the subject that cannot be summarised here so, for the sake of practicality, it will be assumed that a public body sets out to achieve a minimum threshold of accessibility for all its citizens. Those who lie beneath this threshold in the "base case" will do so for a range of reasons, including low income; personal needs or 
circumstances that make conventional transport difficult and/or expensive to use; lack of access to or capacity to drive a car combined with the absence of a viable public transport service; and a home location that is a long journey from key services.

On the face of it, AVs present public authorities with an exceptional opportunity to bring most of these individuals up to the stipulated accessibility threshold: free or subsidised AV travel could address problems of low income, access to/capacity to use a car, and inadequate public transport. Depending on how accessibility is measured, it may not be possible for AVs on their own to overcome problems of remoteness or of network sparsity but this is not a shortcoming of AVs per se. And AVs may provide a solution for those who find conventional forms of transport difficult to use, depending on individual circumstances and the way AVs operate: it seems likely that AVs could serve a large proportion of those with mobility impairments (Fagnant and Kockelman 2015; Ticoll 2015), and a well-designed user interface may prove manageable for many people with learning disabilities or sensory impairments.

There is a strong, if inconsistent, history of government intervention to enhance the accessibility of certain groups, the most prominent UK example being the policy of offering concessionary bus fares to older citizens and some people with disabilities (Butcher 2015). So the use of AVs in the way described would not be a radical departure, though it may be costly. Just as the National Health Service is facing the financial consequences of having ever more sophisticated (and, therefore, more expensive) treatments available (NHS England 2013), transport authorities may find it impossible to provide the desired level of accessibility using AVs (Wagner et al. 2014). Rather, it is feared that the benefits of AVs will be enjoyed by the wealthiest, at least to begin with, given the likely cost of using them (Bierstedt et al. 2014; Thomopoulos and Givoni 2015; Enoch 2015). Moreover, if a segregated network were created to enable AVs to reap the benefits of the technology, and regular users paid a premium for its use, allocating some of its capacity to assisting needier members of society may prove unpopular.

To return to the opening question, should authorities pursue an optimum? This discussion has identified some of the considerable inherent challenges, not least that of selecting the optimum to begin with. Of the two candidate optima discussed, there appeared a more obvious policy fit between AVs and increasing accessibility. In light of the difficulties identified with intervening to pursue objectives relating to either accessibility or capacity, it is legitimate to ask again whether laissez faire is not therefore a preferable mode of governance. The directive authority will be criticised for the strictures it imposes in pursuing the chosen optimum and for any perceived failure to reach its target; the laissez-faire authority may be criticised for not identifying and pursuing an agenda and will certainly be criticised if its citizens find they are unable to do as they wish, as a result of congestion, for example. But perhaps a more significant risk of laissez-faire is best expressed in the quotation attributed to Laurence J Peter: "If you don't know where you are going, you will probably end up somewhere else" (Peter 1977, p.125).

\section{Conclusions and recommendations}

The discussion of various topics above has been necessarily tentative given the level of uncertainty. Nonetheless, several conclusions can be drawn on the subject of governance.

With respect to questions of ownership and use, a greater number of negative effects was associated with the owner-user scenario than other scenarios such as shared use. Whilst the shared-use scenario may come about naturally, public authorities could act to promote it. Where public-sector intervention appears 
essential is in integrating $\mathrm{AVs}$ with existing mass transit, in terms of infrastructure planning and encouraging travellers to use the services. Without this intervention, many mass transit services could struggle to survive and traffic levels on the highways may well become unsustainable.

Discussion of operating environments concluded that AVs will fit better in some locations and types of highway setting than others and that they are equally likely to deliver benefits unevenly, with reason to think that, if not segregated from other traffic, they are less likely to improve traffic conditions especially in urban areas. This likely variety of impact could inform a useful policy development exercise, based on a spatial comparison of likely AV benefit with known transport need.

With respect to the integration of AVs with mixed traffic, it was argued that the current presumption that they will protect life at all costs is very likely to be modified into a more nuanced position in order that they may travel at useful speeds in the vicinity of other road users, broadly consistent with existing norms that demand reasonable care on the part of all road users. But it is not possible to say at present what the dynamic relationship between demand and traffic speed might mean for any new "equilibrium" on the road and, in particular, whether congestion could be expected to improve or worsen compared to current conditions. This uncertainty about network performance further emphasises the significance of segregation as a policy option: authorities can choose to apply it so that AVs may deliver more benefits but at possibly considerable cost to other road users, not least in terms of reduced accessibility.

The role of the public sector was then explored in more general terms from the perspective of level of intervention: should authorities "wait and see" or take deliberate action to guide the development and implementation of self-driving technology? Looking at various ways in which authorities might intervene, several challenges were identified with the interventionist approach, many of them relating to the likely acceptability of measures such as pricing or the imposition of security measures that may be seen as infringing personal liberty. A connected hypothetical discussion of the pursuit of one or other optimum by a transport authority drew similar conclusions but found more social potential in pursuing accessibility as a goal than capacity. None of these explorations, however, automatically demonstrated the superiority of a laissez-faire approach to the governance of AV technology. Laissez-faire has the advantage of freeing authorities from having to justify interventionist policies but brings the considerable risk of backlash if this approach does not deliver the outcomes stakeholders seek, for example if traffic conditions should worsen rather than improve. One specific conclusion was that much might be gained by testing the opinions of citizens and others prior to any implementation.

These conclusions help to reinforce the case for several of the recommendations made as part of the work for the UK Department for Transport described in the introduction. Those recommendations were as follows:

- Development of scenarios for technological \& market developments, use of \& response to AVs

- Transport network simulation exercise

- Exploration and appraisal of the potential role of the public sector

- Deliberative exercise with citizens and organisations to investigate attitudes and likely behavioural responses to the technology

The development of scenarios is intended to help manage the uncertainty associated with this technology. A small number of scenarios would be developed that would, between them, articulate a wide range of plausible futures involving both the nature of the technology and the responses of consumers and others. In particular, the scenarios would have very broad scope, thereby allowing a greater number of interactions to be captured than has been the case in work done to date. They could 
helpfully then inform a network simulation exercise that would enable some early understanding of what might be expected to happen as AVs entered the traffic mix.

The investigation of the public sector's role strongly echoes much of the discussion in this paper. This exercise would enable public authorities to understand the range of policy options available to them and, tentatively, to assess the likely impacts of their adoption, particularly with respect to the pursuit of their objectives.

The deliberative exercise is intended to move beyond the rather mixed quality of most attitudinal surveys done to date on the topic of AVs. As recommended to the Department for Transport, it would draw, if possible, on the set of scenarios to be developed.

Three non-research recommendations were also made to the Department for Transport:

- The establishment of a cross-government AV research panel, reflecting the fact that the benefits and costs of AVs are likely to spread well beyond the purview of the Department for Transport alone;

- A summit of major funders of transport research, designed to co-ordinate activity in an area which is currently being very intensively, though inconsistently, researched

- Deliberative events/exercises for officials, drawing on the stakeholder workshops conducted as part of the scoping study, and designed to enable policy makers to identify any preconceptions they may have about AVs, positive or negative, and to appreciate the very broad range of this technology's possible impacts.

In closing, this is a nascent technology and the research conducted on it to date reflects this. But, as a socio-technical system (Nye 2007), AVs raise major questions of governance. Even if the conclusion is in favour of laissez faire, this should be on the basis of having first thoroughly examined the potential of public bodies to promote the advantages and manage the disadvantages of this technology. 


\section{References}

Adams, J. (2015) Self-Driving Cars and the Child-Ball Problem: Why Autonomous Vehicles Are Not the Answer. London Essays. Available at: http://essays.centreforlondon.org/issues/technology/selfdriving-cars-and-the-child-ball-problem-why-autonomous-vehicles-are-not-the-answer/ [Accessed 19th August 2016].

Alessandrini, A.; Alfonsi, R.; Delle Site, P. \& Stam, D. (2014) Users' preferences towards automated road public transport: Results from european surveys. Transportation Research Procedia. 3, pp. 139-144. Available at: http://ac.els-cdn.com/S2352146514002622/1-s2.0-S2352146514002622main.pdf? tid=ee8d6576-a0d3-11e6-b4aa00000aab0f26\&acdnat $=1478074458 \_f 28 \mathrm{c} 73 \mathrm{f} 9772 \mathrm{~cd} 395 \mathrm{f} 5184295 \mathrm{fc} 96501 \mathrm{~d}$ [Accessed 1st November 2016].

Alessandrini, A.; Campagna, A.; Site, P. D.; Filippi, F. \& Persia, L. (2015) Automated vehicles and the rethinking of mobility and cities. In: Transportation Research Procedia. 5, pp.145-160.

Anderson, J. M.; Kalra, N.; Stanley, K. D.; Sorensen, P.; Samaras, C. \& Oluwatola, O. A. (2014) Autonomous Vehicle Technology. A Guide for Policymakers. RAND Corporation. Available at: http://www.rand.org/content/dam/rand/pubs/research_reports/RR400/RR443-2/RAND_RR4432.pdf [Accessed 1st November 2016].

Aoki, K. (2004) The development of intelligent multimode transit system based on automated buses. In: Proceedings of the 8th International Conference on Automated People Movers, San Francisco, CA, USA, 8-11 July 2001. Available at: https://www.scopus.com/inward/record.uri?eid=2-s2.074949110547\&partnerID $=40 \&$ md5=2db875be12519df322c69f5e1912932e [Accessed 5th November 2016].

Balko, R., 2011. Grieving Mother Faces 36 Months In Jail For Jaywalking After Son Is Killed By HitAnd-Run Driver. The Huffington Post. Available at: http://www.huffingtonpost.com/radleybalko/raquel-nelson-jail-for-jaywalking_b_905925.html [Accessed November 16, 2016].

Bansal, P.; Kockelman, K. M. \& Singh, A. (2016) Assessing public opinions of and interest in new vehicle technologies: An Austin perspective. Transportation Research Part C: Emerging Technologies. 67, pp. 1-14.

BBC News, 2009. East Coast hand-back day 'agreed'. Available at: http://news.bbc.co.uk/1/hi/england/8342435.stm [Accessed November 16, 2016].

Begg, D. (2014) A 2050 vision for London: what are the implications of driverless transport? Clear Channel.

Benmimou, A.; Lowson, M.; Marques, A.; Giustiniani, G. \& Parent, M. (2009) Demonstration of advanced transport applications in CityMobil project. Transportation Research Record: Journal of the Transportation Research Board. 2110, pp. 9-17.

Bierstedt, J.; Gooze, A.; Gray, C.; Peterman, J.; Raykin, L. \& Walters, J. (2014) Effects of NextGeneration Vehicles on Travel Demand and Highway Capacity. Fehr \& Peers. Available at: 
http://orfe.princeton.edu/ alaink/Papers/FP_NextGenVehicleWhitePaper012414.pdf [Accessed 2nd November 2016].

Bohm, F. \& Häger, K. (2015) Introduction of Autonomous Vehicles in the Swedish Traffic System. Effects and Changes Due to the New Self-Driving Car Technology. Uppsala Universitet. Available at: https://uu.diva-portal.org/smash/get/diva2:816899/FULLTEXT01.pdf [Accessed 2nd November 2016].

Bonnefon J.-F.; Shariff, A. \& Rahwan I. (2016) The social dilemma of autonomous vehicles. Science. 352(6293), pp. 1573-1574.

Brombacher, A. (2014) (Re)liability of self-driving cars. An interesting challenge! Quality and Reliability Engineering International. 30(5), pp. 613-614.

Brown, P.-M. (2016) Autonomous Vehicles : A thought leadership review of how the UK can achieve a fully autonomous future. The Institution of Engineering and Technology. Available at: http://www.theiet.org/sectors/transport/documents/av-tst-report-file.cfm?type=pdf [Accessed 2nd November 2016].

Butcher, L., 2015. Concessionary bus fares, Available at: http://researchbriefings.files.parliament.uk/documents/SN01499/SN01499.pdf [Accessed November 17, 2016].

Centre for Connected and Autonomous Vehicles, 2016. Pathway to Driverless Cars: Proposals to support advanced driver assistance systems and automated vehicle technologies, Available at: https://www.gov.uk/government/uploads/system/uploads/attachment_data/file/536365/driverlesscars-proposals-for-adas-and avts.pdf [Accessed November 16, 2016].

Cepolina, E. M.; Farina, A. \& Holloway, C. (2011) A car sharing system for urban areas with fully automated personal vehicles. In: Proceedings of the 13th International Conference on Harbour, Maritime \& Multimodal Logistics Modelling and Simulation, Rome, Italy, 12-14 September 2011. Available at: https://www.researchgate.net/profile/Catherine_Holloway/publication/236008417_Modelling_of_ urban_pedestrian_environments_for_simulation_of_the_motion_of_small_vehicles/links/5535e67 00cf218056e92abb0.pdf [Accessed 5th November 2016].

Chebbi, O. \& Chaouachi, J. (2014) An elitist multi-objective genetic algorithm for minimizing vehicle numbers and energy consumption in the context of Personal Rapid Transit. In: 2014 International Conference on Advanced Logistics and Transport, Hammamet, Tunisia, 1-3 May 2014.

Choromanski, W.; Grabarek, I.; Kowara, J. \& Kaminski, B. (2013) Personal rapid transit - Computer simulation results and general design principles. In: Leder, W. H. \& Sproule, W. J. (ed.) (2013) Automated People Movers and Transit Systems 2013: Half a Century of Automated Transit - Past, Present, and Future. Proceedings of the 14th International Conference on Automated People Movers and Automated Transit Systems, Phoenix, AZ, USA, 21-23 April 2013. ASCE. pp. 276295.

Clark, B.; Parkhurst, G. \& Ricci, M. (2016a) The potential impact of autonomous vehicles on transport systems and society: A review and future prospects. In: 48th Universities' Transport Studies Group Conference, Bristol, UK, 6-8 January 2016. 
Clark, B.; Parkhurst, G. \& Ricci, M. (2016b) Understanding the socioeconomic adoption scenarios for autonomous vehicles: A literature review. University of the West of England, Bristol. Available at: http://eprints.uwe.ac.uk/29134/1/Venturer-LitReview-5-1-Report-Final.pdf [Accessed 2nd November 2016].

Clerget, V.; Hafez, N.; Parent, M. \& Zvirin, Y. (2001) Low cost, trackless PRT. In: Griebenow, R. R. \& Tadi, R. R. (ed.) (2001) Automated People Movers: Moving Through the Millenium. Proceedings of the Eight International Conference on Automated People Movers, San Francisco, CA, USA, 811 July 2001. ASCE. pp. 1-11.

Davis, S.L., 2011. Transportation For America - Update on Raquel Nelson: petition delivered to Cobb County. Transportation for America. Available at: http://t4america.org/2011/10/21/update-onraquel-nelson-petition-delivered-to-cobb-county/ [Accessed November 16, 2016].

Department for Transport, 2016. Single departmental plan 2015 to 2020. GOV.UK. Available at: https://www.gov.uk/government/publications/dft-single-departmental-plan-2015-to-2020/singledepartmental-plan-2015-to-2020 [Accessed July 24, 2016].

Department for Transport, About. Available at: https://www.gov.uk/government/organisations/department-for-transport/about [Accessed December 29, 2014].

Department for Transport, Scottish Government \& Welsh Assembly Government, 2015. Reported Road Casualties Great Britain: 2014 Annual Report, Available at: https://www.gov.uk/government/uploads/system/uploads/attachment_data/file/568484/rrcgb2015.pdf [Accessed November 16, 2016].

Department for Transport. (2015) The Pathway to Driverless Cars Summary report and action plan. DfT Publications. Available at: https://www.gov.uk/government/uploads/system/uploads/attachment_data/file/401562/pathwaydriverless-cars-summary.pdf [Accessed 6th November 2016]

Department of the Environment, Transport and the Regions, 1998. A New deal for Transport: Better for everyone, London: DETR. Available at: http://webarchive.nationalarchives.gov.uk/+/http:/www.dft.gov.uk/about/strategy/whitepapers/prev ious/anewdealfortransportbetterfo5695 [Accessed November 17, 2016].

DiClemente, J.; Mogos, S. \& Wang, R. (2014) Autonomous Car Policy Report. Carnegie Mellon University. Available at: https://www.cmu.edu/epp/people/faculty/coursereports/Autonomous\%20Car\%20Final\%20Report.pdf [Accessed 2nd November 2016].

Enoch, M. P. (2015) How a rapid modal convergence into a universal automated taxi service could be the future for local passenger transport. Technology Analysis \& Strategic Management. 27(8), pp. 910924.

European Commission, 2012. Regulation (EC) No 661/2009 of the European Parliament and of the Council with respect to type-approval requirements for certain categories of motor vehicles with regard to advanced emergency braking systems, Available at: http://eur-lex.europa.eu/legalcontent/EN/TXT/PDF/?uri=CELEX:32012R0347\&from=en [Accessed July 11, 2016]. 
Fagnant, D. J. \& Kockelman, K. (2015) Preparing a nation for autonomous vehicles: opportunities, barriers and policy recommendations. Transportation Research Part A: Policy and Practice. 77, pp. 167-181.

Fox, S. J. (2016) Planning for Density in a Driverless World. Georgetown Law Library. Available at: http://scholarship.law.georgetown.edu/cgi/viewcontent.cgi?article=1000\&context=ipr papers [Accessed 2nd November 2016].

Fraedrich, E.; Beiker, S. \& Lenz, B. (2015) Transition pathways to fully automated driving and its implications for the sociotechnical system of automobility. European Journal of Futures Research. 3(11). Available at: http://link.springer.com/article/10.1007/s40309-015-0067-8 [Accessed 2nd November 2016].

Frisoni, R.; Dall'Oglio, A.; Nelson, C.; Long, J.; Vollath, C.; Ranghetti, D. \& McMinimy, S. (2016) SelfPiloted Cars: the future of road transport? Steer Davies Gleave \& European Parliament, Committee on Transport and Tourism. Available at: http://www.europarl.europa.eu/RegData/etudes/STUD/2016/573434/IPOL_STU(2016)573434_E N.pdf [Accessed 2nd November 2016].

Gayle, D., (2013), Government ditches plans to raise motorway speed limit to $80 \mathrm{mph}$ amid safety concerns and fears it will alienate women voters. Daily Mail Online. Available at: http://www.dailymail.co.uk/news/article-2346316/Government-ditches-plans-raise-motorwayspeed-limit-80mph-amid-safety-concerns-fears-alienate-women-voters.html [Accessed November $17,2016]$.

GOV.UK, Horizon Scanning Programme team. Available at: https://www.gov.uk/government/groups/horizon-scanning-programme-team [Accessed November $8,2016]$.

Guerra, E. (2015) Planning for Cars That Drive Themselves. Metropolitan Planning Organizations, Regional Transportation Plans, and Autonomous Vehicles. Journal of Planning Education and Research. 36(2), pp. 210-224.

Heydecker, B.G., 2016. Network Models of Route Choice. Mathematics Today, pp.212-218.

Horrell, P., 2016. VW to build self-driving cars 'faster than competition'. Top Gear. Available at: http://www.topgear.com/car-news/geneva-motor-show/vw-build-self-driving-cars-fastercompetition [Accessed November 16, 2016].

Howard, D. \& Dai, D. (2013) Public perceptions of self-driving cars: the case of Berkeley, California. In: 93rd Annual Meeting of the Transportation Research Board, Washington DC, USA, 12-16 January 2014. Available at: https://www.ocf.berkeley.edu/ djhoward/reports/Report\%20$\% 20$ Public\%20Perceptions\%20of\%20Self\%20Driving\%20Cars.pdf [Accessed 3rd November 2016].

International Transport Forum. (2015) Automated and Autonomous Driving. Regulation under uncertainty. OECD. Available at: http://www.itfoecd.org/sites/default/files/docs/15cpb_autonomousdriving.pdf [Accessed 3rd November 2016]. 
KPMG \& Center for Automotive Research. (2012) Self-driving cars: The next revolution. KPMG. https://www.kpmg.com/US/en/IssuesAndInsights/ArticlesPublications/Documents/self-drivingcars-next-revolution.pdf [Accessed 3rd November 2016].

KPMG \& SMMT, 2015. Connected and Autonomous Vehicles - The UK Economic Opportunity, KPMG. Available at: https://www.smmt.co.uk/wp-content/uploads/sites/2/CRT036586F-Connected-andAutonomous-Vehicles-\%E2\%80\%93-The-UK-Economic-Opportu...1.pdf [Accessed November $16,2016]$.

KPMG. (2015) Automobile insurance in the era of autonomous vehicles. KPMG. Available at: https://www.kpmg.com/US/en/IssuesAndInsights/ArticlesPublications/Documents/automobileinsurance-in-the-era-of-autonomous-vehicles-survey-results-june-2015.pdf [Accessed 3rd November 2016].

Lam, A. Y. S.; Leung, Y. W. \& Chu, X. (2014) Autonomous vehicle public transportation system. In: Proceedings of the 3rd International Conference on Connected Vehicles and Expo, Austria, Vienna, 3-7 November 2014.

Le Vine, S. \& Polak, J. (2014) Automated Cars: A smooth ride ahead? Independent Transport Commission. Available at: http://www.theitc.org.uk/docs/114.pdf [Accessed 3rd November 2016].

Lowson, M. V. (2011). Sustainable personal transportation. In: Proceedings of the 2011 IEEE Forum on Integrated and Sustainable Transportation Systems, Vienna, Austria, 29 June-1 July 2011.

McKinsey. (2015) Competing for the connected customer - perspectives on the opportunities created by car connectivity and automation. McKinsey\&Company. Available at: http://www.mckinsey.com/ /media/mckinsey/industries/automotive\%20and\%20assembly/our\%20 insights/how\%20carmakers\%20can\%20compete\%20for\%20the\%20connected\%20consumer/comp eting for the connected customer.ashx. [Accessed 1st November 2016].

MIT Media Lab, Moral Machine. Moral Machine. Available at: http://moralmachine.mit.edu [Accessed November 17, 2016].

NHS England, 2013. The NHS belongs to the people, NHS England. Available at: https://www.england.nhs.uk/wp-content/uploads/2013/07/nhs_belongs.pdf [Accessed November $15,2016]$.

Nye, D.E., 2007. Technology matters: questions to live with, Cambridge, Mass.: MIT Press.

Ofcom, 2016. What is internet traffic management? Available at: https://www.ofcom.org.uk/phonestelecoms-and-internet/advice-for-consumers/advice/internet-traffic-management [Accessed November 16, 2016].

Peter, L.J. ed., 1977. Peter's quotations: ideas for our time, New York: Morrow.

Ramsey, M. \& Nagesh, G., 2016. GM, Lyft to Test Self-Driving Electric Taxis. Wall Street Journal. Available at: http://www.wsj.com/articles/gm-lyft-to-test-self-driving-electric-taxis-1462460094 [Accessed November 16, 2016]. 
SAE International, 2016. Taxonomy and Definitions for Terms Related to Driving Automation Systems for On-Road Motor Vehicles, SAE International. Available at: http://standards.sae.org/j3016_201609/ [Accessed November 23, 2016].

Schoettle, B. \& Sivak, M. (2015) Potential Impact of self-driving vehicles on household vehicle demand and usage. University of Michigan, Transportation Research Institute. Available at: https://deepblue.lib.umich.edu/bitstream/handle/2027.42/110789/103157.pdf [Accessed 3rd November 2016].

Schwanen, T. (2016) Rethinking resilience as capacity to endure: Automobility and the city. City. 20(1), pp. 152-160.

Smiley, A. \& Brookhuis, K. A. (1987) Alcohol, drugs, and traffic safety. In Rothengatter, J. A. \& de Bruin, R. A. (ed.) (1987) Road Users and Traffic Safety. Assen, Van Gorcum. pp. 83-105.

Smith, B. W. (2012) Managing Autonomous Transportation Demand. Santa Clara Law Review. 52(4), pp. 1401-1422. Available at:

http://digitalcommons.law.scu.edu/cgi/masouviewcontent.cgi?article=2733\&context=lawreview [Accessed 3rd November 2016].

The Society for the Diffusion of Useful Knowledge, 1866. British Almanac and Companion 1866, London: Knight \& Co. Available at:

https://books.google.co.uk/books?id=WJ4FAAAAQAAJ\&redir_esc=y [Accessed November 16, 2016].

Thomopoulos, N. \& Givoni, M. (2015) The autonomous car--a blessing or a curse for the future of low carbon mobility? An exploration of likely vs. desirable outcomes. European Journal of Futures Research. 3(14). Available at: http://link.springer.com/article/10.1007/s40309-015-0071-z [Accessed 3rd November 2016].

Ticoll, D. (2015) Driving Changes: Automated Vehicles in Toronto. Discussion Paper. University of Toronto Transportation Research Institute. Available at: http://uttri.utoronto.ca/files/2016/04/Driving-Changes-Automated-Vehicles-in-Toronto.pdf [Accessed 3rd November 2016].

Transport for London, 2014. Improving the health of Londoners: Transport action plan, London: Transport for London. Available at: http://content.tfl.gov.uk/improving-the-health-of-londonerstransport-action-plan.pdf [Accessed November 16, 2016].

Transport for London, 2015. Roads Task Force Progress report: a successful first year, London: Transport for London. Available at: http://content.tfl.gov.uk/roads-task-force-update-report-april2015.pdf [Accessed March 11, 2016].

Urry, J., 2013. Are driverless cars a part of the future? Mobile Lives Forum. Available at: http://en.forumviesmobiles.org/60sec/2013/12/04/are-driverless-cars-part-future-1974 [Accessed November 17, 2016].

Wadud, Z.; MacKenzie, D. \& Leiby, P. (2016) Help or hindrance? The travel, energy and carbon impact of highly automated vehicles. Transportation Research Part A: Policy and Practice. 86, pp. 1-18. 
Wagner, J.; Baker, T.; Goodin, G. \& Maddox, J. (2014) Automated vehicles: policy implications scoping study. Texas A\&M Transportation Institute. Available at: http://static.tti.tamu.edu/swutc.tamu.edu/publications/technicalreports/600451-00029-1.pdf [Accessed 3rd November 2016].

Wolmar, C. (2016) Transport's favourite myth: Why we will never own driverless cars. New Statesman. April 10th, 2016. Available at: http://www.newstatesman.com/culture/observations/2016/04/transports-favourite-myth-why-wewill-never-own-driverless-cars [Accessed 3rd November 2016].

Young, K. L. \& Rudin-Brown, C. M. (2014) Designing automotive technology for cross-cultural acceptance. In: Regan, M. A.; Horberry, T. \& Stevens, A. (ed.) (2014) Driver Acceptance of New Technology: Theory, Measurement and Optimisation. CRC Press, Routledge. pp. 317-331.

\section{Appendix - conceptual framework}

There are two main characteristics that contribute to the complexity of this subject:

- The extent of uncertainty

- The multiple links between factors (for example, attitudes informing government action, thereby influencing technological development and hence uptake, and thus leading back to attitudes etc.)

As part of the study for the Department for Transport, it was considered necessary to simplify these relationships significantly to make them manageable. The resultant conceptual framework represents an attempt to capture the strongest relationships between factors and, at the same time, provide a pragmatic way of dealing with uncertainty.

\section{The categories within the framework}

The core of the framework (see Figure A.1) has five categories:

- Technological \& market developments - the set of actions that will determine the AV "offer"

- Use of \& reaction to AVs - how AVs will be purchased or accessed; to what extent, in what ways and by whom they will be used (e.g. privately or collectively); and how other road users will respond

- Consequences/wider impacts - the range of first- and higher-order impacts of AV use, ranging from network performance to well-being, many involving consideration of social and behavioural issues

- Stakeholders' awareness \& attitudes - the role of belief and opinion on the part of individuals and organisations, users and non-users of the technology, in shaping the technology, its uptake and the various consequences of uptake 
- Public sector's role - the scope for government at all levels (whether explicit or implicit) to affect the forms of technology, their uptake and the consequences of uptake; and the policy issues that are likely to arise

Outside the core are Global trends/drivers, serving to demonstrate that the AV "system" is subject to a wide range of external influences; and Monitoring \& consequential actions which represents the element of the feedback process in which actors seek to correct relationships that are perceived to be leading to unwelcome outcomes. 
Figure A.1. Conceptual framework

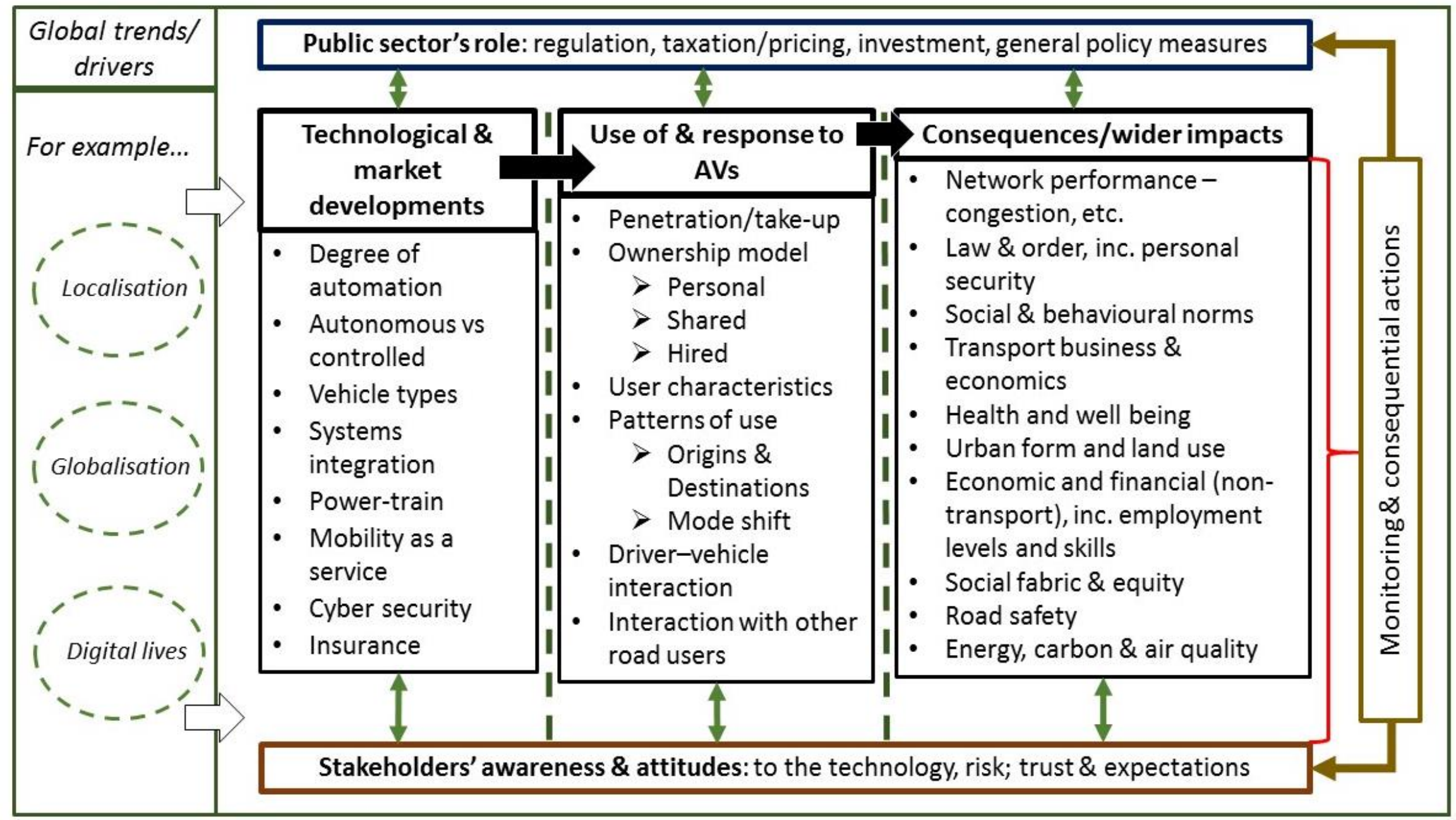




\section{Interactions within the framework}

Whilst, in reality, there is a highly complex set of interactions within and between the categories, the principal flows within the framework are linear, represented by large solid arrows, with feedback loops:

Technological \& market developments is the first step, (of course influenced to some extent by exogenous factors). Use of $\&$ response to AVs covers the set of reactions to what technologies are offered by the market(s). Finally, consequences/wider impacts are the set of effects that are propagated by the pattern of AV uptake and use. The diagram shows both Stakeholders' awareness \& attitudes and Public sector's role as interacting with each of these three steps: for example, the nature of the AV offer will be significantly influenced by the regulations imposed by public bodies; equally, the extent to which AVs are taken up will be a function of stakeholder beliefs concerning their desirability, affordability, safety, and so forth.

This admittedly simplistic set of relationships is helpful in demonstrating that predictions concerning consequences/wider impacts rely upon either evidence or assumptions concerning the preceding two categories - Technological \& market developments; and Use of \& reaction to AVs. A central recommendation to the Department for Transport was therefore the development of a set of scenarios designed to "map out" some of the plausible combinations of AV offer and consumer response. These scenarios could then be used as a platform for research into consequences/wider impacts.

The conceptual framework relates to the structure of this paper as follows: Possible models of ownership and use and Potential strengths and weaknesses of different operating environments and regimes are both located mainly on the left-hand side of the conceptual framework. The remaining three sections are based more in the area of Consequences/wider impacts, though with a strong emphasis on governance throughout.

\section{Notes} group at a time) or small bus ("ride-sharing" amongst more than one user group). Shared-use AVs may be owned by businesses, public bodies or individuals who lease them out some or all of the time.

If a motorway congestion charge took the form of a flat rate per unit distance, this may avoid any claim of discriminating against a particular journey length whilst at the same time making a long journey expensive. But, for now (and quite possibly in the future), motorway crowding is inconsistent and is most pronounced in the vicinity of cities, so to charge for long distances travelled on relatively quiet stretches of road may prove unworkable. familiar E-hailing company is Uber. 
7 Under the "relative safe following" model, acceptable spacing is a function of vehicle length, time between incident and response, and speed. It is generally expected that the time element will be shorter for AVs than for human drivers (though not zero). Hence, the speed at which flow reaches its maximum may be higher in the case of AVs than for cars and a speed increase on motorways may be accompanied by an increase in capacity.

To be clear, Fez does not suit the kinds of AVs that have been produced to date, nor the various future design concepts encountered in the literature. This does not mean that an AV "fit for Fez" could not be designed, but it does seem unlikely. It is another matter to ask whether the people of Fez would want such a vehicle.

The point at which traffic speed reduces may be much higher than in the present scenario of manually driven cars but it would nonetheless be reached at some point.

11 "Trolley problems" are philosophical thought experiments in which a decision has to be made between two or more perilous outcomes. In addition to exploring the relative value of different lives, trolley problems address questions of action and omission. "Moral Machine" is a web-based tool which invites users to consider trolley problems involving AVs (MIT Media Lab n.d.).

12 The nature of this optimum is discussed in the next section.

13 In this section, "optimum" is used in the context of a performance indicator selected by a public-sector body as an appropriate proxy for its aims and objectives. The optimum is the most desirable point on that performance indicator (i.e. the one which represents most progress towards the body's aims/objectives), often (though not always) the maximum.

14 It is interesting to note, then, that the UK Department for Transport's Single Departmental Plan (which tracks its performance against its objectives), concentrates on punctuality (public transport) and delay (highways) (Department for Transport 2016).

Whilst pricing deters some people from travelling by the mode in question, others are encouraged to depart at a quieter (i.e. cheaper) time or to choose a less trafficked (i.e. cheaper) route. At peak times, pricing will lead to increased traffic speed and, hence, typically greater flow. 
